\title{
Photo-induced decomposition of organic peroxides: Ultrafast formation and decarboxylation of carbonyloxy radicals $\dagger$
}

\author{
Michael Buback,* Matthias Kling, $\ddagger$ Stefan Schmatz and Jörg Schroeder \\ Institut für Physikalische Chemie, Universität Göttingen, Tammannstr. 6, \\ D-37077 Göttingen, Germany
}

Received 19th July 2004, Accepted 5th October 2004

First published as an Advance Article on the web 4th November 2004

\begin{abstract}
Recent experimental and theoretical studies shed new light on the ultrafast photochemical decomposition of organic peroxides, $\mathrm{R}_{1} \mathrm{C}(\mathrm{O}) \mathrm{O}-\mathrm{OR}_{2}$. This reaction both is of fundamental interest, directed toward a detailed understanding of unimolecular processes, and of practical relevance because of the widespread use of peroxides as initiators in free-radical polymerization. An overview is given on pico- and femtosecond UV pump-VIS/near IR/IR probe experiments on the decomposition of diaroyl peroxides $\left(\mathrm{R}_{1}=\operatorname{aryl}, \mathrm{R}_{2}=\mathrm{C}(\mathrm{O})-\mathrm{R}_{1}\right)$, of tert-butyl peroxyesters $\left(\mathrm{R}_{1}=\right.$ aryl or benzyl, $\mathrm{R}_{2}=$ tert-butyl), and of tert-butyl peroxycarbonates $\left(\mathrm{R}_{1}=\operatorname{aryloxy}\right.$,

$\mathrm{R}_{2}=$ tert-butyl). Analysis of the time-resolved concentration profiles is carried out in conjunction with quantumchemical calculations, in particular on the structure and reactivity of the intermediate carbonyloxy radicals, $\mathrm{R}_{1}-\mathrm{CO}_{2}$. A semi-quantitative model is presented which allows for an adequate understanding of the ultrafast processes subsequent to instantaneous peroxide photodissociation.
\end{abstract}

\section{Introduction}

Spectroscopic experiments with time resolution in the subpicosecond range allow for very detailed studies of elementary kinetic processes and mechanisms. A group of molecules for which the thorough understanding of reactivity on an ultrashort time-scale is of both fundamental as well as applicationoriented interest are organic peroxides. Photochemical or thermal decomposition of these materials yields radicals that may initiate macromolecular growth in free-radical polymerization. Successful initiation encompasses several elementary kinetic steps between the primary dissociation event of the parent peroxide molecule and the final addition of a peroxidederived free-radical species to a monomer molecule. The early stages of this kinetic sequence may be visualized by inspection of the structure of the peroxyester molecule in Fig. 1. In technical polymerization, a wide variety of such peroxyesters are used, with $\mathrm{R}$ and $\mathrm{R}^{\prime}$ mostly being alkyl groups. ${ }^{1,2}$ The type of $\mathrm{R}$ moiety, in particular the type of $\alpha$-carbon atom in $\mathrm{R}$, whether it is primary $\left(\mathrm{CH}_{3}\right.$ or $\left.\mathrm{CH}_{2} \mathrm{R}\right)$, secondary $\left(\mathrm{CHR}_{2}\right)$, or tertiary $\left(\mathrm{CR}_{3}\right)$, strongly affects dissociation dynamics. ${ }^{3}$ With a tertiary carbon atom, such as in peroxypivalates, initial scission of the $\mathrm{O}-\mathrm{O}$ bond (solid arrow in Fig. 1) is almost instantaneously followed by decarboxylation (dotted arrow in Fig. 1), whereas with a primary carbon atom as, e.g., in peroxyacetates, decarboxylation is a relatively slow process which occurs on a nano- to microsecond time-scale. Whether or not decarboxylation takes place during the initial caged situation of the two primary radicals from peroxide decomposition, is of eminent importance for the initiator efficiency of a particular peroxide. ${ }^{3,4}$ To a good approximation, initiator efficiency may be correlated with the probability that primary radicals escape from the solvent cage prior to undergoing mutual disproportionation or combination reactions (other than the one which restores the parent peroxide). Fast decarboxylation of the

$\dagger$ Electronic supplementary information (ESI) available: Transient absorbance plots (Figures) and calculated harmonic vibrational frequencies (Tables). See http://www.rsc.org/suppdata/cp/b4/b410875b/ $\ddagger$ Current address: FOM Institute for Atomic and Molecular Physics (AMOLF), Kruislaan 407, 1098 SJ Amsterdam, The Netherlands. intermediate carbonyloxy radical lowers initiator efficiency, as disproportionation or combination reactions between the resulting carbon-centered radical and the initially formed oxygen-centered radical $\left(\mathrm{OC}\left(\mathrm{CH}_{3}\right)_{2} \mathrm{R}^{\prime}\right.$, see Fig. 1) may occur which eliminate the radical functionalities. Combination subsequent to decarboxylation produces an ether molecule which, under typical thermal initiation conditions, will be unable to dissociate again. In addition to lowering initiator efficiency, decarboxylation may affect polymer properties, as the produced carbon-centered radicals have chain-transfer activities that are significantly below the ones of oxygen-centered radicals.

Decarboxylation of the intermediate carbonyloxy radical is a $\beta$-scission process which becomes very fast in case the produced carbon-centered radical is relatively stable, as is the tertbutyl radical. Also the "alcohol-side" fragment from peroxyester decomposition, $\mathrm{OC}\left(\mathrm{CH}_{3}\right)_{2} \mathrm{R}^{\prime}$ may undergo $\beta$-scission ${ }^{5}$ (dashed arrow in Fig. 1) which is associated with the formation of a ketone. The latter process again will be extremely fast, and thus will occur in-cage, if $\mathrm{R}^{\prime}$ is a relatively stable radical as, e.g., is the tert-butyl in the decomposition of tetramethylpropyl peroxyesters. ${ }^{5,6}$ Radicals that exit the cage will not necessarily be the species which actually start chain growth. Additional $\beta$ scission reactions or radical-molecule chain-transfer processes may take place before addition to a monomer molecule occurs, typically after time intervals of a microsecond to a millisecond.

To provide a sound basis for the understanding of the various types of follow-up reactions after $\mathrm{O}-\mathrm{O}$ bond scission of peroxides $\mathrm{R}_{1} \mathrm{C}(\mathrm{O}) \mathrm{O}-\mathrm{OR}_{2}$, the mechanism and the time-scale of the decarboxylation process of initially produced

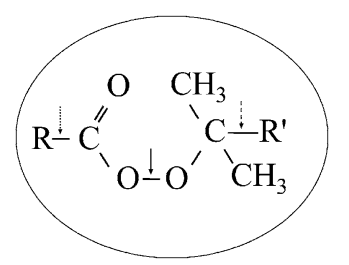

Fig. 1 Structure of a peroxyester molecule with $\mathrm{R}$ and $\mathrm{R}^{\prime}$ being alkyl groups. Arrows indicate bonds that do or may break in the decomposition. See text for further details. 
carbonyloxy species needs to be addressed first. Femtosecond pump-probe experiments are extremely valuable for this purpose. In order to carry out such experiments with laser excitation at wavelengths $\geq 248 \mathrm{~nm}$, diaroyl peroxide $\left(\mathrm{R}_{1}=\right.$ aryl, $\left.\mathrm{R}_{2}=\mathrm{C}(\mathrm{O})-\mathrm{R}_{1}\right)$, tert -butyl peroxyesters $\left(\mathrm{R}_{1}=\right.$ aryl or benzyl, $\mathrm{R}_{2}=$ tert-butyl), and tert-butyl peroxycarbonates $\left(\mathrm{R}_{1}=\right.$ aryloxy, $\mathrm{R}_{2}=$ tert-butyl) have been chosen for our investigations. Such compounds exhibit suitable absorptivity at the pump wavelengths.

The light-induced decarboxylation of these organic peroxides, $\mathrm{R}_{1} \mathrm{C}(\mathrm{O}) \mathrm{O}-\mathrm{OR}_{2}$, is assumed to occur as a sequential process consisting of two unimolecular dissociation steps, the peroxide $\mathrm{O}-\mathrm{O}$ bond dissociation and the decarboxylation of the carbonyloxy intermediate, to yield radicals $R_{1}$ and $\mathrm{OR}_{2}$ plus $\mathrm{CO}_{2}$. Scheme 1 shows these two decomposition steps. Photo-excitation of the peroxides into their $\mathrm{S}_{1}$ electronically excited state initially produces the radicals $\mathrm{R}_{1} \mathrm{C}(\mathrm{O}) \mathrm{O}$ and $\mathrm{OR}_{2}$. Sequential decarboxylation, via $\mathrm{R}_{1} \mathrm{C}(\mathrm{O}) \mathrm{O}$, is favored over concerted two-bond scission because different types of bonds and thus different bond energies are involved in these two processes. $^{7}$

While extensive literature exists on the thermal decomposition of diacyl peroxides and peroxyesters, ${ }^{2,3}$ until recently photochemical peroxide decomposition primarily was investigated with nano- and microsecond time resolution using flash photolysis in conjunction with VIS or EPR spectroscopy. ${ }^{8-15}$ Experiments at such time resolution provide insight into the principal reaction channels and into structural aspects of peroxide decomposition, but are unable to reveal mechanistic details of photodissociation dynamics. ${ }^{10,16}$ Further progress has been achieved by carrying out experiments with subnanosecond time resolution. ${ }^{4,17-24}$ Short-lived species could be detected in picosecond studies. ${ }^{24}$ The formation and the vibrational cooling of $\mathrm{CO}_{2}$ in solution have only recently been monitored on a picosecond time scale via IR detection. ${ }^{42,23}$ These UV pump-IR probe experiments revealed that there are processes occurring on a sub-picosecond time-scale. The decarboxylation of the benzylcarbonyloxy radical has been investigated on a fs time-scale by Bockman et al. ${ }^{25}$

Until the results of time-resolved experiments with a time resolution of a few picoseconds and below became available, the existing data on thermal as well as on photochemical peroxide decompositions were not sufficient for establishing a quantitative model providing a detailed understanding of dissociation dynamics. In particular, the dependence of the dynamics on peroxide structure, on internal energy after initial bond scission, and on solvent environment were not adequately understood. ${ }^{3,4}$ In general, the difficulties in modeling peroxide decomposition are associated with competing processes, such as vibrational cooling of initially hot intermediates, ${ }^{21,26,27}$ not being quantitatively known. Moreover, analysis of measured transient absorption signals may be obscured by spectral congestion of parent molecules, intermediates and products. ${ }^{8,13,14}$ A thorough analysis of the dissociation dynamics requires transient spectroscopy over extended ranges of probe wavelengths with high temporal and spectral resolution. Within the investigations underlying the present article, highly timeresolved spectroscopic investigations were carried out from the IR through the near-IR to visible probe wavelengths. In addition, it appears mandatory to accompany the experimental studies by quantum-chemical calculations in order to map out

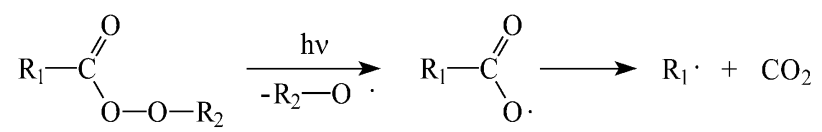

Scheme 1 Sequential dissociation after UV excitation of diaroyl peroxides $\left(\mathrm{R}_{1}=\right.$ aryl, $\left.\mathrm{R}_{2}=\mathrm{C}(\mathrm{O})-\mathrm{R}_{1}\right)$, tert-butyl arylperoxyesters $\left(\mathrm{R}_{1}=\right.$ aryl or benzyl, $\mathrm{R}_{2}=$ tert-butyl $)$, and tert-butyl peroxycarbonates $\left(\mathrm{R}_{1}=\right.$ aryloxy, $\mathrm{R}_{2}=$ tert-butyl). molecular structures, energies, vibrational frequencies, as well as the relevant features of the potential energy surfaces (PESs) on which the reactions proceed.

The present article summarizes ultrafast absorption spectroscopy experiments and quantum-chemical studies on the decarboxylation of carbonyloxy radicals from the decomposition of organic peroxides $\mathrm{R}_{1} \mathrm{C}(\mathrm{O}) \mathrm{O}-\mathrm{OR}_{2}$ in solution. For the decarboxylation step, a semi-quantitative model will be provided, which is based on statistical unimolecular rate theory and on density functional theory (DFT) calculations. The seven diaroyl peroxides, two tert-butyl peroxyesters, and two tert-butyl peroxycarbonates under investigation are displayed in Scheme 2. These are: (i) the diaroyl peroxides di(benzoyl) peroxide (DBPO), di(2-methylbenzoyl) peroxide (D2MBP), di(4-methylbenzoyl) peroxide (D4MBP), di(4-methoxybenzoyl) peroxide (D4MOP), di(2,4-dichlorobenzoyl) peroxide (D24CB), di(1-naphthoyl) peroxide (D1NPO), and di(2naphthoyl) peroxide (D2NPO); (ii) the tert-butyl peroxyesters tert-butyl peroxybenzoate (TBPB) and tert-butyl phenylperoxyacetate (TBPPA); (iii) the peroxycarbonates tert-butyl phenylperoxycarbonate (TBPPC) and tert-butyl 2-naphthyl peroxycarbonate (TBNC). The data for D2MBP, D4MBP, $\mathrm{D} 24 \mathrm{CB}$, and D2NPO are presented here for the first time.

The article is organized as follows: In Section II, the experimental techniques and quantum-chemical methods are described. In Section III, a model for representing the sequential decomposition of organic peroxides is presented together with the procedure for analyzing time-resolved traces of carbonyloxy concentration. The model is based on data from quantum-chemical calculations, which are summarized in Section IVA. Results from time-resolved experiments on the formation and decarboxylation of carbonyloxy radicals will be presented in Section IVB. In Section V the results of modeling the spectroscopic data and the dependence of carbonyloxy radical reactivity on molecular structure will be discussed. Section VI concludes the article.

\section{Experimental techniques and quantum-chemical methods}

\section{A. Experimental}

Two experimental setups were used for the time-resolved investigation of carbonyloxy radical decomposition. In experiment $\mathrm{I}$, the production of $\mathrm{CO}_{2}$ and the vibrational energy transfer from $\mathrm{CO}_{2}$ to the solvent environment was monitored by transient UV pump-IR probe spectroscopy with picosecond time resolution..$^{4,22,23}$ In experiment II, the formation and decarboxylation of carbonyloxy radicals, $\mathrm{R}_{1} \mathrm{C}(\mathrm{O}) \mathrm{O}$, as well as the formation of product radicals $\mathrm{R}_{1}$, has been recorded with femtosecond UV pump-VIS-near IR probe spectroscopy. ${ }^{17-21}$ As the experimental setups have been described in detail elsewhere, ${ }^{28,29}$ only a very brief description will be given here.

In experiment I, the setup is based on a home-built excimer laser-pumped (Lambda Physik EMG 150) cascade dye laser system for the generation of pulses at either 497 or $616 \mathrm{~nm}$ with a repetition rate of $10 \mathrm{~Hz} .{ }^{4,28}$ These pulses were frequencydoubled and amplified in the second tube of the excimer laser to obtain UV pump pulses at either 248.5 or $308 \mathrm{~nm}$ with typical energies of a few millijoules. The remainder of the pulses at 497 or $616 \mathrm{~nm}$ served for both pumping a prismatic distributed feedback dye laser, delivering signal pulses between 550 and $595 \mathrm{~nm}$ (with the $497 \mathrm{~nm}$ pulse) or between 700 and $850 \mathrm{~nm}$ (with the $616 \mathrm{~nm}$ pulse) ${ }^{4,28}$ and for generating the fundamental pulses for difference frequency generation (DFG). IR probe pulses ranging from 3 to $5.1 \mu \mathrm{m}$ with spectral widths between 10 and $15 \mathrm{~cm}^{-1}$ were produced by DFG of signal and fundamental pulses in a $\mathrm{LiIO}_{3}$ crystal and were recorded by InSb photo-detectors (EG\&G J10D M-204). The pump and 


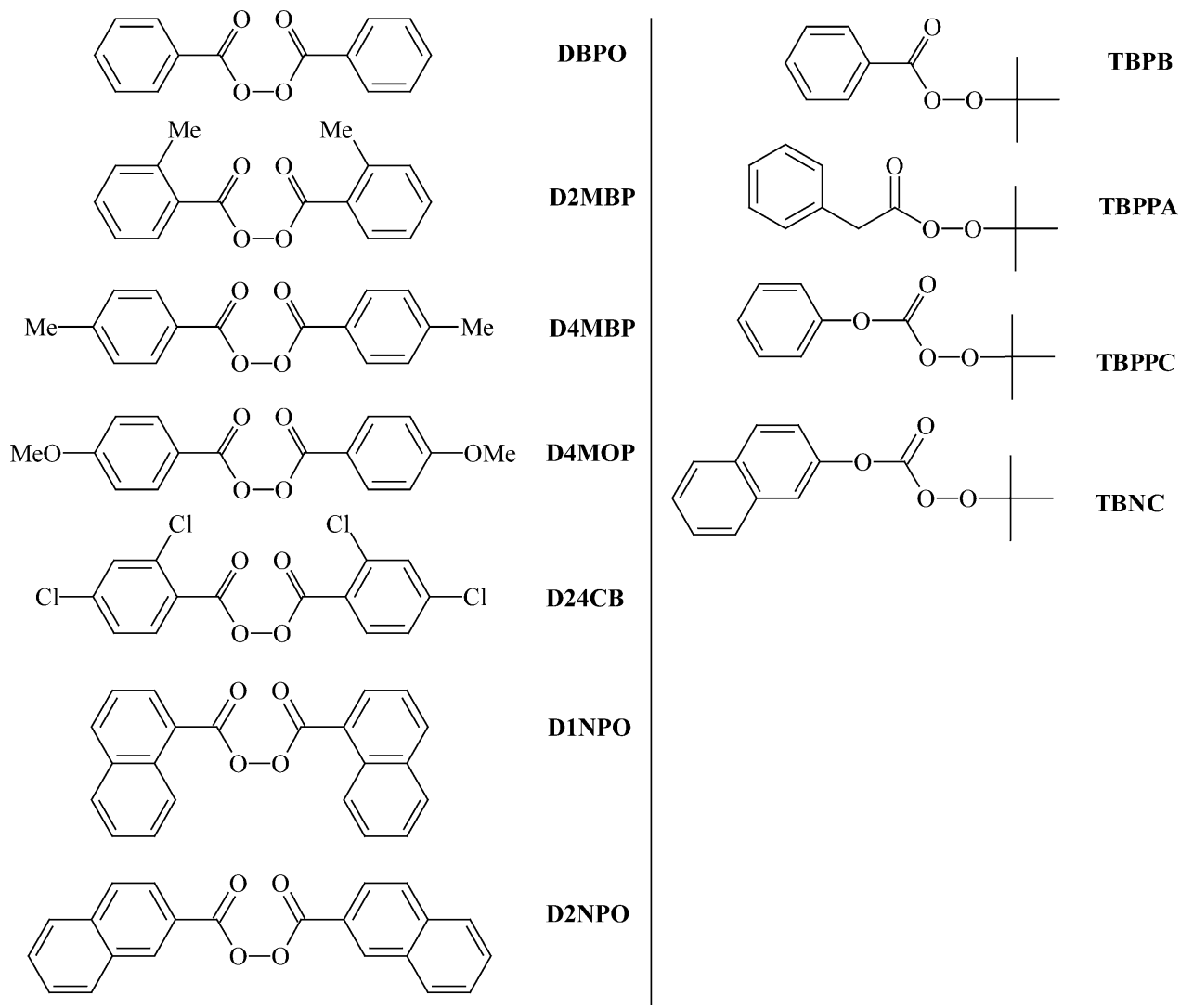

Scheme 2 Diaroyl peroxides (left) and tert-butyl peroxyesters and carbonates (right) discussed in this article.

probe laser pulses were overlapped spatially and temporally in a traveling wave (pump at $308 \mathrm{~nm}$ ) or at nearly collinear pump-probe geometry $\left(10^{\circ}\right)$ (pump pulse at $248.5 \mathrm{~nm}$ ) in a fast-flow cell. The polarization between pump and probe pulses was adjusted to $54.7^{\circ}$ (magic angle). The minimum detectable transient absorbance was $\Delta \mathrm{OD} \approx 0.001$ and the time resolution about 2 ps.

In the UV pump-VIS/near IR probe studies (experiment II), a commercial Ti:sapphire regenerative amplifier system (CPA2001, Clark-MXR) was used to pump two optical parametric amplifiers (TOPAS, Light Conversion and NOPA, ClarkMXR). The TOPAS output was frequency-mixed to provide probe pulses in the wavelength range from 290 to $1000 \mathrm{~nm}$. Tunable pump pulses $(230-350 \mathrm{~nm})$ were obtained by second harmonic generation of the NOPA signal. Some of the experiments were carried out with a home-built Ti:sapphire based regenerative laser amplifier system (VERDI, Coherent, ORC1000, Clark-MXR). ${ }^{28,29}$ The output of this system was used for both harmonic frequency generation of $266 \mathrm{~nm}$ pump pulses and to pump a TOPAS for delivering probe pulses in the 290 to $1000 \mathrm{~nm}$ range. Pump and probe pulses were weakly focused $(f=200 \mathrm{~mm})$ and overlapped spatially and temporally at nearly collinear pump-probe geometry $\left(5^{\circ}\right)$ in a fast-flow cell ( 0.1 to $0.2 \mathrm{~mm}$ thickness). Pulses with relative polarization at $54.7^{\circ}$ were chosen for the experiments. Probe pulse intensities were recorded at $1 \mathrm{kHz}$ repetition rate. The transient absorbance detection limit and time resolution of experiment II were $\Delta \mathrm{OD}=5 \times 10^{-5}$ and 100 to $200 \mathrm{fs}$, respectively.

All peroxide samples were synthesized in high purity and kindly provided by Akzo Nobel Polymer Chemicals (Deventer, The Netherlands). Solvents of highest available quality were purchased from Merck. Both the peroxides and the solvents were used without further purification.

\section{B. Quantum-chemical methods}

Although the calculations of molecular structures and energies were performed for isolated molecules, the results are expected to be applicable to reactions in liquid non-polar and even weakly polar aprotic solution as studied in our spectroscopic experiments.

The DFT variant $\mathrm{UB} 3 \mathrm{LYP}^{30}$ in conjunction with basis sets of increasing size $[6-31 G(d), 6-311+G(d, p), 6-311+G(2 d, p)$, and $6-311+(2 \mathrm{df}, 2 \mathrm{pd})]$ was used in the electronic structure calculations. The program package GAUSSIAN98 was employed throughout. ${ }^{31}$ For each of the radicals, the four relevant stationary points (reactants, products, and first-order saddle points pertinent to decarboxylation and internal rotation of the $\mathrm{CO}_{2}$ group) on the potential energy surfaces (PESs) were first fully optimized using the $6-31 \mathrm{G}(\mathrm{d})$ basis set. The optimized geometries were then further refined employing the 6-311+ $\mathrm{G}(\mathrm{d}, \mathrm{p})$ basis set which in particular contains diffuse functions to describe the loose character of the transition states. We also carried out additional single-point calculations with the two larger basis sets using the previously optimized geometries. All stationary points were characterized by calculation of the Hessian matrices, while transition state structures were further confirmed by following the minimum energy paths (MEPs) using the intrinsic reaction coordinate (IRC) method. ${ }^{32}$

For the benzoyloxy radical, large-scale coupled cluster calculations were carried out in ref. 17 and a comparison with the UB3LYP geometries revealed that the latter are highly reliable for the investigated type of carbonyloxy radicals. The errors are in the order of $0.001 \AA$ and $1^{\circ}$ for bond distances and angles, respectively. Moreover, we could not find any significant difference in the geometries and energies of carbonyloxy radicals obtained from calculations employing the DFT variants UB3LYP and UB3PW91. Changes due to basis saturation effects have only a minor influence, as is commonly observed for DFT methods. The error due to basis set truncation (basis set superposition error, BSSE) is estimated to be very small because the basis set limit is reached much faster in density functional theory than in conventional wave-functionbased methods.

It is well-known that unrestricted single-determinant wave functions (such as unrestricted Hartree-Fock, UHF) exhibit a 
large spin contamination with aryl and benzyl radicals. ${ }^{33}$ Although such a spin contamination would certainly affect molecular geometry and energies, it was shown that spin contamination in unrestricted density functional calculations is usually small (no spin contamination would occur in DFT calculations if the exact functionals were known). ${ }^{34}$ Hybrid density functionals such as B3LYP have a somewhat higher spin contamination due to the admixture of Hartree-Fock exchange. In all our calculations, the deviation of the average $\left\langle S^{2}\right\rangle$ values from the eigenvalues $S(S+1)=0.75$ does not exceed $5 \%$. Thus spin contamination does not affect our results.

\section{Modeling the decarboxylation of carbonyloxy radicals}

A quantitative description of photo-induced carbonyloxy radical decarboxylation needs to be based on an adequate picture of the photodissociation dynamics of the parent peroxide. UVirradiation of small organic peroxides such as di-tert-butyl peroxide $^{35}$ and tert-butyl hydroperoxide ${ }^{36}$ at wavelengths around $220 \mathrm{~nm}$ is known to excite an $\sigma^{*} \leftarrow \mathrm{n}$ transition at the $\mathrm{O}-\mathrm{O}$ bond causing $\mathrm{O}-\mathrm{O}$ bond rupture and direct dissociation to tert-butoxy radicals which may fragment in subsequent reaction steps. As $\mathrm{O}-\mathrm{O}$ bond scission is extremely fast, intramolecular redistribution of the vibrational energy (IVR) among the vibrational modes of the peroxide may be incomplete prior to dissociation. Thus the energy distribution of the nascent radicals may be non-statistical. On the other hand, subjecting the aroyl peroxides investigated in our study to laser pulses of wavelengths between 250 and $310 \mathrm{~nm}$ populates either the lowest singlet excited state via an $\pi^{*} \leftarrow \mathrm{n}$ transition, or the second excited singlet state via a $\pi^{*} \leftarrow \pi$ transition, or a superposition of both states. While the dynamics following $\pi^{*} \leftarrow \mathrm{n}$ excitation may favor fast $\mathrm{O}-\mathrm{O}$ bond rupture, $\pi^{*} \leftarrow \pi$ excitation is most unlikely to cause breaking of the $\mathrm{O}-\mathrm{O}$ bond in a direct process. Instead, the resulting dynamics is expected to closely resemble the one encountered in the photodissociation of cumene hydroperoxide excited to its lowest $\left(\pi, \pi^{*}\right)$ state. ${ }^{37}$ In this case, absorption of a $193 \mathrm{~nm}$ photon induces a much slower indirect dissociation occurring via a conical intersection between the bound $\left(\pi, \pi^{*}\right)$ and the repulsive $\left(n, \sigma^{*}\right)$ states with a rate constant determined by the predissociation lifetime of the $\left(\pi, \pi^{*}\right)$-state. However, experimental data seem to indicate that in this case the non-statistical character of the energy distribution prior to bond breaking is less pronounced. Still, it is exclusively the $\mathrm{O}-\mathrm{O}$ bond that is broken in the initial photochemical reaction step. $\mathrm{O}-\mathrm{O}$ bond fission was also found to be the primary step in the fragmentation of di-tert-butyl peroxide induced by triplet-triplet energy transfer ${ }^{38}$ and in the collision induced decomposition of DBPO,${ }^{39}$ supporting the generally agreed view that the thermal decarboxylation of organic peroxides in solution has to be regarded as a sequential process.

On the basis of these main characteristics of peroxide decarboxylation, i.e. a sequential mechanism and ultrafast primary bond scission, we analyze our measured concentration changes assuming that the excited state of the peroxide molecule does not absorb probe light at the respective observation wavelengths at times later than about $300 \mathrm{fs}$ after excitation, i.e. after leaving the Franck-Condon region. Therefore, the transient absorption we observe on a picosecond time scale is assigned entirely to carbonyloxy and product radicals.

Our model of carbonyloxy decarboxylation rests on a few additional assumptions which we regard as justified under the conditions of our studies:

(i) Photodissociation of organic peroxides may result in vibrationally excited carbonyloxy radicals in the ground and excited electronic state, depending on the energetic separation between these states and on the excitation energy. (ii) Vibrationally hot ground state radicals will decarboxylate in a fast "thermal" reaction across a small energy barrier in competition with vibrational cooling by energy transfer to the solvent. "Thermal" is meant to imply that IVR in carbonyloxy radicals is complete prior to decarboxylation.

(iii) As at least one excited state of the carbonyloxy radical correlates with product ground states, electronically excited carbonyloxy radicals can dissociate in a direct, barrier-less "downhill reaction" to vibrationally excited products. IVR prior to dissociation is not necessarily complete for this channel. In any case, dissociation via the electronically excited state of the carbonyloxy radical is expected to be too fast to be resolved with a time resolution of $200 \mathrm{fs}$, i.e., on the time-scale of our experiments, products from this channel will be observed instantaneously.

(iv) Geminate recombination of intermediate and/or product radicals may be neglected, as may addition to $\mathrm{CO}_{2}$.

(v) The solvent merely acts as a heat bath and has no effect on the potential energy surface in the region which is relevant for carbonyloxy decarboxylation, i.e. in our model we may, without further correction, use the results from quantumchemical calculations for isolated species.

We now turn to modeling the ground state reaction illustrated in Fig. 2 using statistical (RRKM) rate theory and an approximate description of the vibrational cooling process in solution. At first, the initial mean vibrational energy, $\left.E_{\text {int(COO}}\right)(t=0)$, of the carbonyloxy radical has to be estimated. The available energy, $E_{\text {ava }}$, after the photodissociation step with excitation frequency $\nu_{\mathrm{exc}}$ is given by

$$
E_{\text {ava }}=E_{\text {int }}^{\text {peroxide }}(300 \mathrm{~K})+h \nu_{\text {exc }}-D(\mathrm{O}-\mathrm{O})
$$

$E_{\mathrm{nt}}^{\text {peroxide }}(300 \mathrm{~K})$ and $D(\mathrm{O}-\mathrm{O})$ denote the mean vibrational energy of the peroxide prior to excitation and the dissociation energy of the $\mathrm{O}-\mathrm{O}$ bond, respectively. For simplicity, we assume that $E_{\text {ava }}$ is statistically distributed among the vibrational modes of both radical fragments, implying that IVR in liquid solution is much faster than in the isolated molecule and is complete prior to breaking the $\mathrm{O}-\mathrm{O}$ bond, and that the fraction of the energy imparted to relative translational motion of the fragments is negligible. Thus we arrive at the approximate expression

$$
E_{\mathrm{int}(\mathrm{COO} \cdot)}(t=0)+E_{\operatorname{int}\left(\mathrm{R}^{\bullet}\right)}(t=0) \approx h \nu_{\mathrm{exc}}-\Delta_{\mathrm{diss}} H^{\ominus},
$$

$\Delta_{\text {diss }} H^{\ominus}$ and $E_{\left.\text {int( } \mathrm{R}^{\bullet}\right)}(t=0)$ being the calculated dissociation enthalpy of the peroxide and the initial mean vibrational energy of the second radical fragment, respectively.

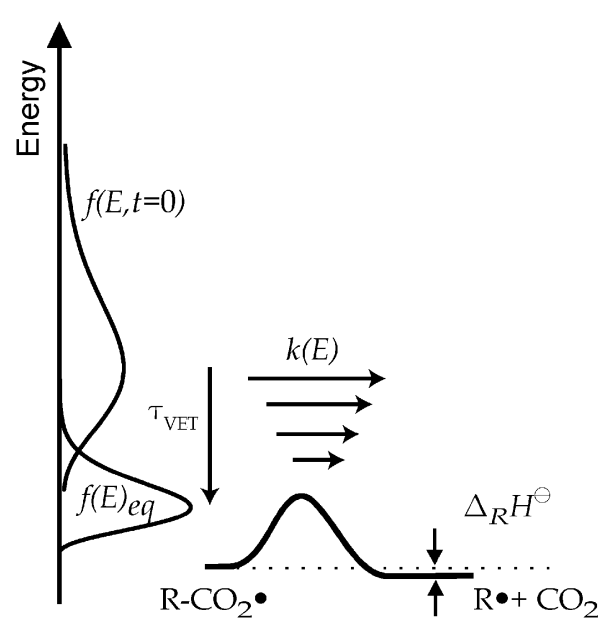

Fig. 2 Modeling the ground state decarboxylation of carbonyloxy radicals. The fast reaction from the hot initial distribution competes with vibrational cooling towards thermal equilibrium, causing the reaction rate to slow down rapidly. See text for details. 
Hence, a common initial vibrational temperature $T_{\mathrm{vib}}(t=0)$ of the intermediate fragment radicals may be calculated according to

$$
E_{\text {ava }}=\sum_{i} \frac{\hbar \omega_{i}}{\exp \left(\hbar \omega_{i} / k_{\mathrm{B}} T_{\mathrm{vib}}(t=0)\right)-1}
$$

using the vibrational normal mode frequencies $\omega_{i}$ of both fragments obtained from DFT calculations. $T_{\mathrm{vib}}(t=0)$ defines an initial Boltzmann energy distribution

$$
f(E, t=0)=\frac{1}{Q_{\mathrm{vib}}(t=0)} \rho(E) \exp \left(-E / k_{\mathrm{B}} T_{\mathrm{vib}}(t=0)\right),
$$

where $Q_{\mathrm{vib}}$ is the corresponding molecular vibrational partition function and $\rho(E)$ the vibrational density of states of the carbonyloxy radical.

As the carbonyloxy radical vibrationally cools as a consequence of energy transfer to the solvent, its vibrational temperature decreases with time. For the $T_{\text {vib }}$ range under consideration it is known $^{27,40}$ that the decrease of the mean excess vibrational energy $\Delta E(t)=E_{\text {int }\left(\mathrm{COO}^{\bullet}\right)}(t)-E_{\text {int }(\mathrm{COO} \cdot)}$ $(t \rightarrow \infty)$ follows an exponential decay characterized by a vibrational energy relaxation time, $\tau_{\mathrm{VET}}$, according to

$$
\Delta E(t)=\Delta E(t=0) \exp \left(-t / \tau_{\mathrm{VET}}\right) .
$$

Applying eqn. (5) is equivalent to describing vibrational energy transfer to the solvent on the basis of the Landau-Teller theory for vibrational energy relaxation of a harmonic oscillator by a master equation, treating the normal modes of the carbonyloxy radical as independent harmonic oscillators. ${ }^{41}$ The relaxation time, $\tau_{\mathrm{VET}}$, enters into our model as a parameter which may be varied only within a narrow range that is determined by the literature values for vibrational relaxation in solution of molecules of similar size and complexity. ${ }^{27,40}$

We now go one step further and convert the resulting timedependent mean vibrational energy, $E_{\text {int }}(t)$, into a time-dependent vibrational temperature and a Boltzmann distribution according to eqns. (3) and (4),

$$
E_{\text {int }}(t)=\sum_{i} \frac{\hbar \omega_{i}}{\exp \left(\hbar \omega_{i} / k_{\mathrm{B}} T_{\mathrm{vib}}(t)\right)-1}
$$

and

$$
f(E, t)=\frac{1}{Q_{\mathrm{vib}}(t)} \rho(E) \exp \left(-E / k_{\mathrm{B}} T_{\mathrm{vib}}(t)\right) .
$$

We have tested this approximation by comparison with timedependent distributions obtained from full master equation simulations which are known to yield Gaussian energy distributions for $0<t<\infty$. As we start out with a fairly broad Boltzmann distribution, the resulting difference between transient absorbance decays simulated with "exact" Gaussian and "approximate" Boltzmann distributions is not significant.

Using the time-dependent energy distributions $f(E, t)$, thermal decarboxylation rate coefficients, $k_{\text {th }}$, (for the high-pressure or transition state theory limit) may be calculated according to

$$
k_{\mathrm{th}}(t)=f_{\mathrm{rot}} \int_{E_{0}}^{\infty} f(E, t) k(E) \mathrm{d} E .
$$

Here, $E_{0}$ is the reaction barrier, and $f_{\text {rot }}=\sqrt{\prod_{i=1}^{3} B_{i} / B_{i}^{\ddagger}}$ accounts for rotational effects, with $B_{i}$ and $B_{i}^{\ddagger}$ being the rotational constants of the ground state carbonyloxy radical in the equilibrium and transition state, respectively. Microcanonical rate coefficients $k(E)$ are calculated from

$$
k(E)=\frac{W^{\ddagger}\left(E-E_{0}\right)}{h \rho(E)},
$$

where $W^{\ddagger}\left(E-E_{0}\right)$ is the number of energetically accessible transition state energy levels at energy $E$. Barrier heights, rotational constants, and harmonic normal mode frequencies for reactants and transition states were taken from our DFT calculations.

Based on this model, transient absorbance decay curves, $S(t)$, may be calculated from

$$
S(t)=A(t) \exp \left(-k_{\mathrm{th}}(t) t\right) .
$$

Decay curves were simulated using a stepwise procedure for time intervals $\Delta t$ at constant internal energy $E_{\text {int }}(t)$. Vibrational energy relaxation was taken into account after each time interval $\Delta t$. The optimum time interval turned out to be $\Delta t=$ 10 fs. A scaling factor $A(t)$ was calculated for each iteration step to generate a continuous profile for connecting the individual time slices. Prior to comparison with experimental data, simulated decay curves $S(t)$ were convoluted with the experimentally determined cross-correlation function.

The principle of the procedure is illustrated in Fig. 3 which depicts the transient absorbance after photodissociation at 266 $\mathrm{nm}$ of D1NPO dissolved in propylene carbonate (PC). Analysis of transient absorption spectra showed that, among the species present, only the 1-naphthyloxycarbonyloxy radical absorbs at the probe wavelength of $390 \mathrm{~nm}$. The fast absorbance decay reflects the decarboxylation of vibrationally hot 1-naphthyloxycarbonyloxy radicals and their rapid cooling to ambient temperature. The plateau-type absorbance at larger $t$ represents the subsequent thermal decarboxylation which occurs on a time scale beyond that of our experiment.

For the simulations we use the initial internal energy of the carbonyloxy radical as estimated from our DFT calculations (in this particular case: $E_{\mathrm{int}}(t=0)=14600 \mathrm{~cm}^{-1}$ ). The barrier height, $E_{0}$, obtained from quantum-chemical calculations is adjusted such as to yield the known thermal decarboxylation rate coefficient for ambient temperature. For the example in Fig. 3, the barrier height which reproduces thermal rate constants reported for decomposition in various solvents (Table 1) is $(9.2 \pm 0.8) \mathrm{kcal} \mathrm{mol}^{-1}$, in good agreement with the value obtained from our quantum-chemical calculations (Table 2). A vibrational relaxation time of $\tau_{\mathrm{VET}}=8 \mathrm{ps}$ turned out to be optimal for most of our simulations. Incidentally, this $\tau_{\mathrm{VET}}$ value is identical to the vibrational relaxation time of the benzoyloxy radical in dichloromethane solution that is obtained from classical equilibrium molecular dynamics simulations based on the Landau-Teller model. ${ }^{42}$ Shown in Fig. 3, by the dotted and dashed lines, is the effect of varying $\tau_{\mathrm{VET}}$ by factors of 0.75 and 1.25 , respectively. The resulting effects clearly demonstrate that there is little room for varying this parameter. The agreement between simulation and experiment is quite remarkable in view of the fact that, with the exception

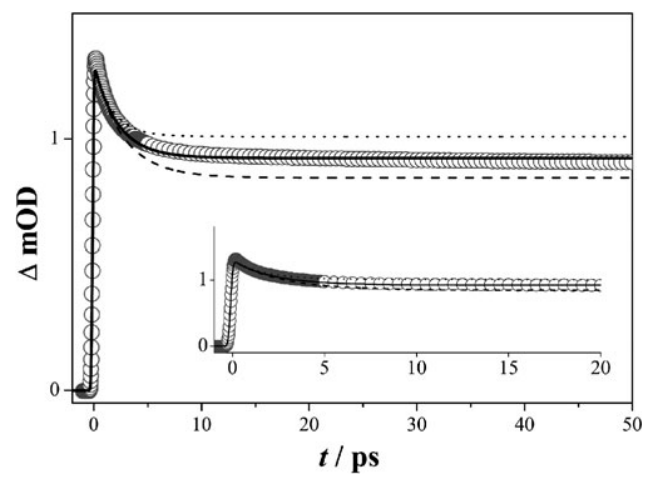

Fig. 3 1-Naphthoyloxy radical transient absorbance at $390 \mathrm{~nm}$ following photodissociation at $266 \mathrm{~nm}$ of D1NPO dissolved in propylene carbonate $(\bigcirc) .{ }^{19}$ Lines represent the results of simulations as described in the text using different values of $\tau_{\mathrm{VET}}: 6$ ps (dotted), 8 ps (full), and 10 ps (dashed). 
Table 1 Rate constants $(k)$, activation energies $\left(E_{\mathrm{a}}\right)$ and frequency factors $(A)$ for the thermal decay of carbonyloxy radicals at ambient temperature

\begin{tabular}{|c|c|c|c|c|c|c|}
\hline & Solvent & $\begin{array}{l}\log \\
\left(A / \mathrm{s}^{-1}\right)\end{array}$ & $\begin{array}{l}E_{\mathrm{a}} / \mathrm{kcal} \\
\mathrm{mol}^{-1}\end{array}$ & $T /{ }^{\circ} \mathrm{C}$ & $10^{-6} \mathrm{k} / \mathrm{s}^{-1}$ & Ref \\
\hline \multirow[t]{3}{*}{$\mathrm{Ph}-\mathrm{CO}_{2}$} & \multirow[t]{2}{*}{$\mathrm{CCl}_{4}$} & 12.6 & 8.6 & 24 & 2.0 & 14 \\
\hline & & 10.8 & 5.8 & 20 & 4.5 & 11 \\
\hline & $\mathrm{CH}_{3} \mathrm{CN}$ & 12.1 & 7.3 & 25 & 5.9 & 13 \\
\hline \multirow[t]{2}{*}{$4-\mathrm{Me}-\mathrm{C}_{6} \mathrm{H}_{4}-\mathrm{CO}_{2}$} & $\mathrm{CCl}_{4}$ & & & 20 & 2.8 & 11 \\
\hline & $\mathrm{CH}_{3} \mathrm{CN}$ & 13.1 & 9.3 & 23 & 1.8 & 49 \\
\hline \multirow[t]{3}{*}{$4-\mathrm{MeO}-\mathrm{C}_{6} \mathrm{H}_{4}-\mathrm{CO}_{2}$} & $\mathrm{CCl}_{4}$ & 12.3 & 9.2 & 24 & 0.34 & 8 \\
\hline & & 13.6 & 11.0 & 25 & 0.41 & 13 \\
\hline & $\mathrm{CH}_{3} \mathrm{CN}$ & & & 25 & 0.1 & 13 \\
\hline \multirow[t]{2}{*}{$2-\mathrm{Nph}-\mathrm{CO}_{2}$} & $\mathrm{CCl}_{4}$ & 13.0 & 8.7 & 25 & 4.0 & 12 \\
\hline & $\mathrm{CH}_{3} \mathrm{CN}$ & 13.1 & 9.0 & 25 & 3.5 & 12 \\
\hline $2-\mathrm{Me}-\mathrm{C}_{6} \mathrm{H}_{4}-\mathrm{CO}_{2}$ & $\mathrm{CH}_{3} \mathrm{CN}$ & 10.5 & 4.1 & 25 & 17 & 50 \\
\hline \multirow[t]{2}{*}{$1-\mathrm{Nph}-\mathrm{CO}_{2}$} & $\mathrm{CCl}_{4}$ & 12.1 & 7.5 & 25 & 5.1 & 12 \\
\hline & $\mathrm{CH}_{3} \mathrm{CN}$ & 13.5 & 10.9 & 25 & 0.32 & 12 \\
\hline
\end{tabular}

of slightly adjusting the barrier height, no parameter fitting is involved. Carbonyloxy radical decarboxylation in the electronic ground state thus appears to be well predictable on the basis of our statistical model using normal mode frequencies, thermochemical data and reaction barriers from quantumchemical calculations as well as a reasonable value of $\tau_{\mathrm{VET}}$.

Modeling becomes more complicated in cases where an electronically excited state of the carbonyloxy radical is populated during peroxide photodissociation and participates in the decarboxylation reaction. This situation is illustrated in Fig. 4. From an electronically excited state that correlates with the electronic ground state of the associated product radical, decarboxylation takes place as an ultrafast direct downhill reaction with a rate constant $k_{\text {direct. }}$. As a consequence, the high-energy tail of the initial energy distribution is rapidly depleted and the ensuing ground state reaction effectively starts from an energy distribution cut off at high energies. The subsequent process follows the pattern that has already been illustrated in Fig. 2. If the energetic position of the excited state was precisely known, one could truncate the initial energy distribution for the ground state reaction accordingly. Without this knowledge, one has to treat the truncated $E_{\text {int }}(t=0)$ for the ground state reaction channel as a fit parameter.

The situation is illustrated in Fig. 5 for benzoyloxy decarboxylation after photodissociation at $282 \mathrm{~nm}$ of TBPB in solution of $n$-heptane. The transient absorbance recorded at $600 \mathrm{~nm}$ is entirely due to benzoyloxy. Fig. 5a shows the result

Table 2 Characteristic geometrical parameters for decarboxylation deduced from UB3LYP $/ 6-311+\mathrm{G}(\mathrm{d}, \mathrm{p})$ calculations: $r(\mathrm{X}-\mathrm{C})$ denotes the distance (in $\AA$ ) between the carboxylic $\mathrm{C}$ atom and the nearest $\mathrm{C}$ atom or the bridging oxygen atom (in group 3 molecules), $\alpha(\mathrm{O}-\mathrm{C}-\mathrm{O})$ is the internal angle of the carboxyl group (in degrees). $\ddagger$ indicates the saddle point structure. Note that the saddle point geometries are planar only for the first four species listed in this table. Distances in $\AA$, angles in degrees

\begin{tabular}{llllll}
\hline & $r(\mathrm{X}-\mathrm{C})$ & $r$ & $r^{\ddagger}(\mathrm{X}-\mathrm{C})$ & $\alpha(\mathrm{O}-\mathrm{C}-\mathrm{O})$ & $\alpha^{\ddagger}(\mathrm{O}-\mathrm{C}-\mathrm{O})$ \\
\hline Group 1 & $\mathrm{Ph}-\mathrm{CO}_{2}$ & 1.472 & 1.875 & 111.9 & 149.1 \\
& 4-Me- $\mathrm{C}_{6} \mathrm{H}_{4}-\mathrm{CO}_{2}$ & 1.469 & 1.894 & 110.8 & 149.8 \\
& 4-MeO-$-\mathrm{C}_{6} \mathrm{H}_{4}-\mathrm{CO}_{2}$ & 1.462 & 1.917 & 110.5 & 150.8 \\
& 2-Nph- $\mathrm{CO}_{2}$ & 1.470 & 1.880 & 110.8 & 149.2 \\
Group 2 & $2,4-\mathrm{Cl}_{2}-\mathrm{C}_{6} \mathrm{H}_{3}-\mathrm{CO}_{2}$ & 1.479 & 1.927 & 112.1 & 153.5 \\
& 2-Me- $\mathrm{C}_{6} \mathrm{H}_{4}-\mathrm{CO}_{2}$ & 1.473 & 1.924 & 110.1 & 151.3 \\
& 1-Nph- $\mathrm{CO}_{2}$ & 1.474 & 1.938 & 109.9 & 151.4 \\
Group 3 & $\mathrm{Ph}-\mathrm{O}-\mathrm{CO}_{2}$ & 1.334 & 1.375 & 116.3 & 123.6 \\
& $\mathrm{Ph}-\mathrm{CH}_{2}-\mathrm{CO}_{2}$ & 1.509 & 1.556 & 113.0 & 124.1 \\
& 2-Nph-O-CO $-\mathrm{CO}_{2}$ & 1.409 & 1.462 & 126.0 & 130.2 \\
\hline
\end{tabular}

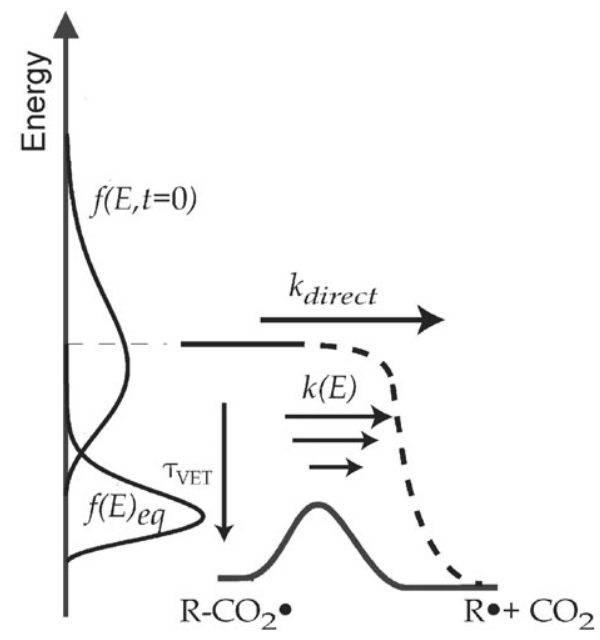

Fig. 4 Modeling competing ground and excited state decarboxylation of carbonyloxy radicals. Following primary photodissociation, the high energy fraction of the initial energy distribution populates the electronically excited state of the radical which leads to rapid decarboxylation in a downhill reaction with a rate constant $k_{\text {direct }}$. The remainder of the distribution populates the electronic ground state. The ground state reaction follows the same pattern as illustrated in Fig. 2 , but starting from an energy distribution that is cut off at high energies. For details of the model, see text.

of attempts to model the experimental trace under the assumption that the reaction exclusively takes place on the ground state potential energy surface (PES). An adjusted barrier height of $E_{0}=(8.95 \pm 0.25) \mathrm{kcal} \mathrm{mol}^{-1}$ is used (which is derived from reproducing the thermal rate constant given in Table 1 and is in excellent agreement with the data from quantum-chemical calculations (Table 3$)^{43}$ ) and $E_{\text {int }}(t=0)=13400 \mathrm{~cm}^{-1}$ is obtained from DFT calculations. Rather poor agreement between simulation and experiment is seen for $\tau_{\mathrm{VET}}=8 \mathrm{ps}$ (dotted line). Only for a significantly smaller vibrational relaxation time, $\tau_{\mathrm{VET}}=5 \mathrm{ps}$, an adequate fit is obtained. As the vibrational relaxation time should, however, be close to $8 \mathrm{ps}$,

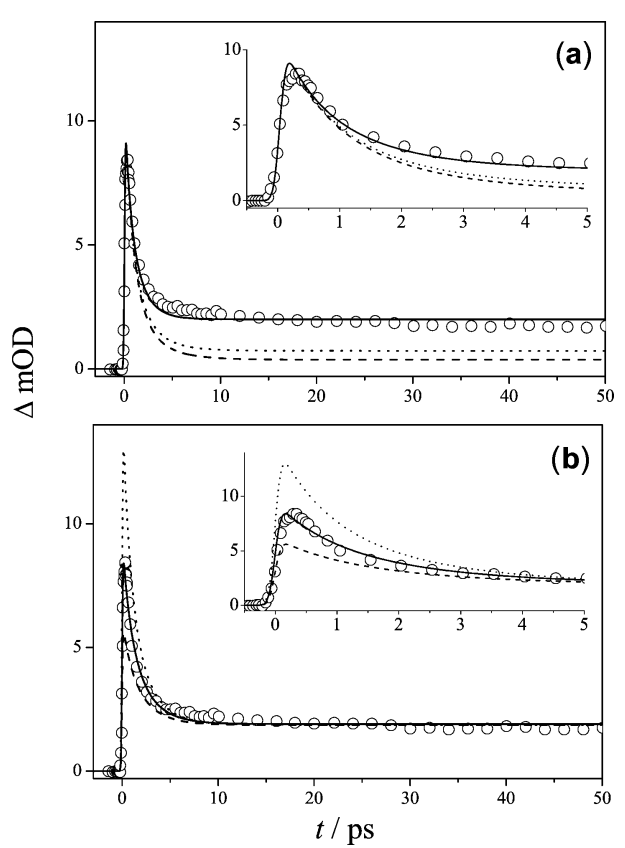

Fig. 5 Benzoyloxy radical transient absorbance at $600 \mathrm{~nm}$ following photodissociation of TBPB at $282 \mathrm{~nm}$ in $n$-heptane $(O) .{ }^{17}$ Lines represent the results of simulations as described in the text using different values of (a) $\tau_{\mathrm{VET}}: 5 \mathrm{ps}$ (solid), 8 ps (dotted), $10 \mathrm{ps}$ (dashed) at fixed $E_{\text {int }}=13400 \mathrm{~cm}^{-1}$, and of (b) $E_{\text {int }}(t=0): 12600 \mathrm{~cm}^{-1}$ (dotted), $11600 \mathrm{~cm}^{-1}$ (solid), $10600 \mathrm{~cm}^{-1}$ (dashed) at fixed $\tau_{\mathrm{VET}}=8 \mathrm{ps}$. 
Table 3 Relative energies of reactants and transition states (in $\mathrm{kcal} \mathrm{mol}^{-1}$ ) for decarboxylation and internal $\mathrm{CO}_{2}$ rotation of carbonyloxy radicals $\mathrm{R}-\mathrm{CO}_{2}$ (UB3LYP results). The energy of the reactant is set to zero for all methods and basis sets. Reaction enthalpies for decarboxylation are also given (in kcal mol${ }^{-1}$ ). $E_{\mathrm{el}}$ denotes the electronic energies, while $E_{0}$ includes corrections due to zero-point vibrational effects (harmonic level). Absolute energy values in $E_{\mathrm{h}}$ are available from the authors upon request

\begin{tabular}{|c|c|c|c|c|c|c|c|}
\hline & \multirow[b]{2}{*}{ Basis set } & \multicolumn{2}{|c|}{$\mathrm{CO}_{2}$ rotation barrier height } & \multicolumn{2}{|c|}{ Decarboxylation barrier height } & \multicolumn{2}{|c|}{ Decarboxylation energy/enthalpy } \\
\hline & & $E_{\mathrm{el}}$ & $E_{0}$ & $E_{\mathrm{el}}$ & $E_{0}$ & $E_{\mathrm{el}}$ & $\Delta_{\mathrm{R}} H^{\circ}(298 \mathrm{~K})$ \\
\hline \multirow[t]{3}{*}{$\mathrm{Ph}-\mathrm{CO}_{2}$} & $6-311+G(d, p)$ & & & 10.0 & 8.5 & -0.1 & -1.2 \\
\hline & $6-311+G(2 d, p)$ & & & $10.8^{a}$ & $9.3^{b}$ & & \\
\hline & $6-311+G(2 d f, 2 p d)$ & $4.0^{a}$ & $3.5^{b}$ & $9.9^{a}$ & $8.4^{b}$ & $-0.4^{a}$ & $-1.5^{c}$ \\
\hline \multirow[t]{3}{*}{$4-\mathrm{Me}-\mathrm{C}_{6} \mathrm{H}_{4}-\mathrm{CO}_{2}$} & $6-311+\mathrm{G}(\mathrm{d}, \mathrm{p})$ & & & 10.7 & 9.2 & 1.1 & -0.03 \\
\hline & $6-311+\mathrm{G}(2 \mathrm{~d}, \mathrm{p})$ & & & $11.3^{a}$ & $9.8^{b}$ & & \\
\hline & $6-311+G(2 d f, 2 p d)$ & $4.0^{a}$ & $3.4^{b}$ & $10.9^{a}$ & $9.4^{b}$ & $1.0^{a}$ & $-0.2^{c}$ \\
\hline \multirow{3}{*}{$4-\mathrm{MeO}-\mathrm{C}_{6} \mathrm{H}_{4}-\mathrm{CO}_{2}$} & $6-311+\mathrm{G}(\mathrm{d}, \mathrm{p})$ & & & 12.1 & 10.5 & 2.9 & 1.8 \\
\hline & $6-311+G(2 d, p)$ & & & $12.8^{a}$ & $11.2^{b}$ & & \\
\hline & $6-311+G(2 d f, 2 p d)$ & $1.2^{a}$ & $0.5^{b}$ & $12.0^{a}$ & $10.4^{b}$ & 2.9 & 1.7 \\
\hline \multirow[t]{3}{*}{$2-\mathrm{Nph}-\mathrm{CO}_{2}$} & $6-311+\mathrm{G}(\mathrm{d}, \mathrm{p})$ & & & 10.5 & 8.9 & 0.4 & -0.7 \\
\hline & $6-311+G(2 d, p)$ & & & $11.1^{a}$ & $9.5^{b}$ & & \\
\hline & $6-311+\mathrm{G}(2 \mathrm{df}, 2 \mathrm{pd})$ & $3.6^{a}$ & $2.9^{b}$ & $10.4^{a}$ & $8.8^{b}$ & $0.3^{a}$ & $-0.9^{c}$ \\
\hline \multirow[t]{3}{*}{$2,4-\mathrm{Cl}_{2}-\mathrm{C}_{6} \mathrm{H}_{3}-\mathrm{CO}_{2}$} & $6-311+\mathrm{G}(\mathrm{d}, \mathrm{p})$ & & & 12.0 & 10.3 & -2.7 & -3.6 \\
\hline & $6-311+G(2 d, p)$ & & & $12.5^{a}$ & $10.9^{b}$ & & \\
\hline & $6-311+\mathrm{G}(2 \mathrm{df}, 2 \mathrm{pd})$ & $2.8^{a}$ & $2.2^{b}$ & $11.7^{a}$ & $10.1^{b}$ & $-2.6^{a}$ & $-3.5^{c}$ \\
\hline \multirow{3}{*}{$2-\mathrm{Me}-\mathrm{C}_{6} \mathrm{H}_{4}-\mathrm{CO}_{2}$} & $6-311+\mathrm{G}(\mathrm{d}, \mathrm{p})$ & & & 9.9 & 8.2 & -1.5 & -2.6 \\
\hline & $6-311+G(2 d, p)$ & & & $10.4^{a}$ & $8.7^{b}$ & & \\
\hline & $6-311+\mathrm{G}(2 \mathrm{df}, 2 \mathrm{pd})$ & $3.4^{a}$ & $2.5^{b}$ & $9.7^{a}$ & $7.9^{b}$ & $-1.5^{a}$ & $-2.7^{c}$ \\
\hline \multirow{3}{*}{$1-\mathrm{Nph}-\mathrm{CO}_{2}$} & $6-311+\mathrm{G}(\mathrm{d}, \mathrm{p})$ & & & 10.0 & 8.5 & -1.9 & -2.9 \\
\hline & $6-311+G(2 d, p)$ & & & $10.5^{a}$ & $9.0^{b}$ & & \\
\hline & $6-311+\mathrm{G}(2 \mathrm{df}, 2 \mathrm{pd})$ & $1.2^{a}$ & $0.3^{b}$ & $9.7^{a}$ & $8.2^{b}$ & $-1.9^{a}$ & $-3.1^{c}$ \\
\hline
\end{tabular}

${ }^{a}$ Calculated using the $6-311+\mathrm{G}(\mathrm{d}, \mathrm{p})$ geometries. ${ }^{b}$ Zero-point energy (ZPE) calculated employing the $6-311+\mathrm{G}(\mathrm{d}, \mathrm{p})$ basis set. ${ }^{c}$ ZPE and thermal corrections for $298 \mathrm{~K}$ calculated with the $6-311+\mathrm{G}(\mathrm{d}, \mathrm{p})$ basis set.

the data in Fig. 5a suggests that the decarboxylation process in Fig. 5 does not entirely proceed as a ground state reaction.

Assuming that an excited state channel contributes, we optimized $E_{\text {int }}(t=0)$ and obtained, as is shown in Fig. 5 b, good agreement between experiment and model simulation at $\tau_{\mathrm{VET}}=8 \mathrm{ps}$. The optimum value of $E_{\mathrm{int}}(t=0)$ turned out to be $2800 \mathrm{~cm}^{-1}$ below the value from DFT that was used for the ground state model (Fig. 5a).

For benzoyloxy, this result may be compared with what is known about electronically excited states of this radical. For this purpose, a simplified energy level diagram is plotted in Fig. 6. Calculations of excited states of benzoyloxy are feasible because of the high symmetry $\left(C_{2 \mathrm{v}}\right)$ of this radical. Vertical transition energies to three singly excited electronic states of ${ }^{2} \mathrm{~A}_{2},{ }^{2} \mathrm{~A}_{1}$ and ${ }^{2} \mathrm{~B}_{1}$ symmetry were found at 6276,12943 , and 21 $075 \mathrm{~cm}^{-1}$ (RCCSD(T)/437 cGTOs), respectively. ${ }^{17}$ The transition from the ground state to the ${ }^{2} \mathrm{~B}_{1}$ state is symmetry

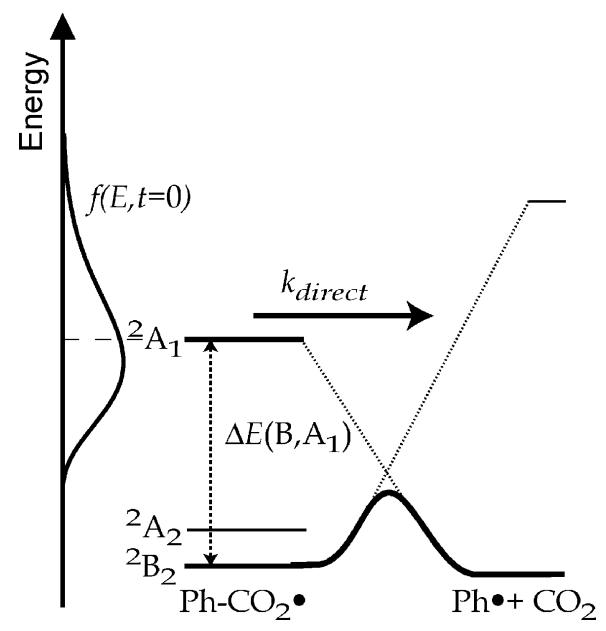

Fig. 6 Energy levels and excited state reaction of the benzoyloxy radical. forbidden. Moreover, due to its rather high excitation energy, the ${ }^{2} \mathrm{~B}_{1}$ state is not expected to play a role in peroxide photodissociation at excitation wavelengths around $250 \mathrm{~nm}$. The transition to the second excited state, ${ }^{2} \mathrm{~A}_{1}$, which is associated with a wavelength of $773 \mathrm{~nm}$, correlates well with a broad absorption band of benzoyloxy radicals. ${ }^{13}$ As described by Pacansky and Brown, ${ }^{44}$ only the ${ }^{2} \mathrm{~A}_{1}$ state correlates with the ${ }^{2} \mathrm{~A}_{1}$ ground state of the phenyl radical.

The ${ }^{2} \mathrm{~A}_{1}$ and ${ }^{2} \mathrm{~B}_{2}$ states in $C_{2 \mathrm{v}}$ symmetry may cross resulting in a conical intersection that could play a crucial role in the nuclear dynamics. However, in reality $C_{2 \mathrm{v}}$ symmetry is probably not maintained along the reaction path because the benzoyloxy radical produced by dissociation of the $\mathrm{O}-\mathrm{O}$ bond in TBPB or in DBPO is highly distorted with respect to its equilibrium geometry. The asymmetric $\mathrm{CO}$ stretch is excited as is the hindered internal rotation around the $\mathrm{Ph}-\mathrm{CO}_{2}$ bond. Since the dissociation barrier is much higher than that for internal rotation (see Table 3), the $\mathrm{CO}_{2}$ group can almost freely rotate at chemically relevant energies. We thus assume that the reaction takes place on a single adiabatic PES, i.e. on the lower of the two surfaces forming the conical intersection in $C_{2 \mathrm{v}}$ symmetry. In this adiabatic approximation a saddle point appears instead of the double cone. Recent DFT calculations carried out without symmetry restrictions, indeed, gave a reasonable saddle point structure and transition mode for the decarboxylation of the benzoyloxy radical. ${ }^{17}$

In carbonyloxy radicals of lower symmetry (point group $C_{\mathrm{s}}$ or $C_{1}$ ), electronically excited states cannot be assigned unambiguously and symmetry correlations between carbonyloxy and product radical states cannot be established. The general considerations may however remain valid also for these carbonyloxy radicals. The location of the excited state responsible for direct decarboxylation of carbonyloxy radicals may be probed via its typical optical transition in the near IR range. ${ }^{13,14}$ It has been shown that excitation of carbonyloxy radicals within this frequency range leads to immediate decarboxylation. ${ }^{45}$

The contribution of direct carbonyloxy fragmentation via the electronically excited state following UV photodissociation 
Table 4 Relative energies of reactants and transition states (in kcal mol ${ }^{-1}$ ) for decarboxylation of carbonyloxy radicals $\mathrm{R}-\mathrm{X}-\mathrm{CO}_{2}$ (UB3LYP results). The energy of the reactant is set to zero for all methods and basis sets. Reaction enthalpies for decarboxylation are also given (in kcal $\left.\mathrm{mol}^{-1}\right) . E_{\mathrm{el}}$ denotes the electronic energies, while $E_{0}$ includes corrections due to zero-point vibrational effects (harmonic level). Absolute energy values in Hartree are available from the authors upon request

\begin{tabular}{|c|c|c|c|c|c|}
\hline & \multirow[b]{2}{*}{ Basis set } & \multicolumn{2}{|c|}{ Decarboxylation barrier height } & \multicolumn{2}{|c|}{ Decarboxylation energy/enthalpy } \\
\hline & & $E_{\mathrm{el}}$ & $E_{0}$ & $E_{\mathrm{el}}$ & $\Delta_{\mathrm{R}} H^{\circ}(298 \mathrm{~K})$ \\
\hline \multirow[t]{2}{*}{$\mathrm{Ph}-\mathrm{O}-\mathrm{CO}_{2}$} & $6-311+G(d, p)$ & 2.3 & 1.3 & -30.9 & -31.9 \\
\hline & $6-311+G(2 d f, 2 p d)$ & $3.2^{a}$ & $2.2^{b}$ & $-29.7^{a}$ & $-30.8^{c}$ \\
\hline \multirow[t]{2}{*}{$\mathrm{Ph}-\mathrm{CH}_{2}-\mathrm{CO}_{2}$} & $6-311+G(d, p)$ & 2.6 & 1.5 & -27.4 & -29.0 \\
\hline & $6-311+\mathrm{G}(2 \mathrm{df}, 2 \mathrm{pd})$ & $2.2^{a}$ & $1.1^{b}$ & $-28.3^{a}$ & $-29.9^{c}$ \\
\hline \multirow[t]{2}{*}{ 2-Nph-O- $\mathrm{CO}_{2}$} & $6-311+G(d, p)$ & 0.06 & -0.5 & -31.7 & -32.3 \\
\hline & $6-311+G(2 d f, 2 p d)$ & $0.05^{a}$ & $-0.5^{b}$ & $-30.6^{a}$ & $-31.2^{c}$ \\
\hline
\end{tabular}

${ }^{a}$ Calculated using the $6-311+\mathrm{G}(\mathrm{d}, \mathrm{p})$ geometries. ${ }^{b}$ ZPE calculated employing the $6-311+\mathrm{G}(\mathrm{d}, \mathrm{p})$ Basis set. ${ }^{c}$ ZPE and thermal corrections for $298 \mathrm{~K}$ calculated with the $6-311+\mathrm{G}(\mathrm{d}, \mathrm{p})$ basis set.

of the peroxide is obviously determined by the location of the excited state energy level with respect to $E_{\text {int }}(t=0)$. For benzoyloxy, the relevant ${ }^{2} \mathrm{~A}_{1}$ excited state is located at about $13000 \mathrm{~cm}^{-1}$, i.e. the fraction of the initial population with energies above this value will be rapidly depleted. For such a case model simulations with variable $E_{\text {int }}(t=0)$ should result in a value significantly smaller than the available energy $E_{\text {ava }}$ which is exactly what we observe for benzoyloxy (see Table 5 later). Representing $E_{\text {int }}(t=0)$ as the mean energy of a vibrational distribution (with a vibrational temperature $T_{\mathrm{av}}$ corresponding to the available energy $E_{\text {ava }}$ ) truncated at $E_{\mathrm{tr}}$,

$$
\left\langle E_{\text {int }}\right\rangle(t=0)=\int_{0}^{E_{\mathrm{tr}}} E f\left(E\left(T_{\text {ava }}\right)\right) \mathrm{d} E
$$

one may estimate, within the framework of a statistical ansatz, the fraction of the population that reacts via the excited state channel $Y_{\text {exc }}$ from

$$
Y_{\mathrm{exc}}=1-\frac{Q_{\mathrm{vib}, \mathrm{tr}}(t=0)}{Q_{\mathrm{vib}}(t=0)}=\frac{\int_{0}^{E_{\mathrm{tr}}} f\left(E\left(T_{\mathrm{ava}}\right)\right) \mathrm{d} E}{\int_{0}^{\infty} f\left(E\left(T_{\mathrm{ava}}\right)\right) \mathrm{d} E} .
$$

For benzoyloxy radicals generated in the photolysis of TBPB at $282 \mathrm{~nm}$ and of DBPO at $266 \mathrm{~nm} Y_{\text {exc }}$ turns out to be $25-60 \%$ in agreement with our earlier estimate of 20 to $50 \%$ based on product radical absorbance measurements. ${ }^{17}$ These results provide evidence that our statistical approach on the basis of quantum-chemical calculations is capable of a quantitative description of photo-induced carbonyloxy radical decarboxy- lation kinetics even in the presence of electronically excited state channels.

\section{Results}

\section{A. Quantum-chemical calculations}

The simulation of measured transient absorbance traces according to the statistical unimolecular rate theory model described in Section III requires several molecular parameters as input data. The most convenient way to obtain this data is by quantum-chemical calculations. Density functional theory methods have proven to be a powerful and efficient tool for calculating geometries of reactants and transition states, rotational constants, reaction barrier heights and vibrational frequencies. ${ }^{17-21,46}$ Our results have exclusively been obtained by using Becke's three-parameter functional (B3LYP) ${ }^{30}$ while comparisons with other functionals have been described elsewhere. ${ }^{17}$ It should be pointed out that high-level coupled cluster calculations yield geometrical parameters very close to our DFT results. ${ }^{17}$

Calculations were carried out for the various substituted phenyl- $\mathrm{CO}_{2}$ species and for the two isomeric naphthyl- $\mathrm{CO}_{2}$ compounds. Results are given in Tables 2 and 3. The decarboxylations are almost thermoneutral. Geometry optimization of the saddle point species pertinent to decarboxylation turned out to be relatively straightforward for those species where the $\mathrm{CO}_{2}$ group is directly coupled to the aromatic system and where no substituent is in the ortho-position of the aromatic ring. For these carbonyloxy species, $\mathrm{Ph}-\mathrm{CO}_{2}, 4-\mathrm{Me}-\mathrm{C}_{6} \mathrm{H}_{4}-$ $\mathrm{CO}_{2}, 4-\mathrm{MeO}-\mathrm{C}_{6} \mathrm{H}_{4}-\mathrm{CO}_{2}$ and 2-Nph- $\mathrm{CO}_{2}$ (group 1), the barriers are of the order of $10 \mathrm{kcal} \mathrm{mol}^{-1}$ (see Table 3 ) and the

Table 5 Simulation results for the decay of carbonyloxy radicals. $f_{\text {rot }}$ is the calculated rotational correction factor. Energies $D_{\mathrm{O}-\mathrm{O}}, E_{0}, E_{\text {ava }}$, and $E_{\text {int }}(t=0)$ are given in units of $\mathrm{kcal} \mathrm{mol}^{-1}$ and denote $\mathrm{O}-\mathrm{O}$ bond energy in the parent peroxide, optimized barrier height, energy available to the carbonyloxy radical after primary $\mathrm{O}-\mathrm{O}$ bond scission, and initial internal energy of the radical used in the model calculation, respectively (see

\begin{tabular}{|c|c|c|c|c|c|c|c|c|c|}
\hline Radical & Parent peroxide; Solvent; $\lambda_{\text {pump }} / \mathrm{nm}$ & $\lambda_{\text {probe }} / \mathrm{nm}$ & $D_{\mathrm{O}-\mathrm{O}}$ & $f_{\text {rot }}$ & $E_{0}$ & $E_{\text {ava }}$ & $E_{\text {int }}(t=0)$ & $\tau_{\mathrm{VET}} / \mathrm{ps}$ & Ref. \\
\hline $4-\mathrm{Me}-\mathrm{C}_{6} \mathrm{H}_{4}-\mathrm{CO}_{2}$ & D4MBP; PC; 266 & 310 & 18.6 & 1.06 & 9.03 & 39.7 & 39.7 & 10 & This work \\
\hline $2,4-\mathrm{Cl}_{2}-\mathrm{C}_{6} \mathrm{H}_{3}-\mathrm{CO}_{2}$ & D24CB; PC; 266 & 340 & 15.7 & 1.03 & 9.89 & 40.9 & 40.9 & 6 & This work \\
\hline $2-\mathrm{Nph}-\mathrm{CO}_{2}$ & D2NPO; PC; 266 & 320 & 19.9 & 1.03 & 9.32 & 39.7 & 39.7 & 8 & This work \\
\hline $4-\mathrm{MeO}-\mathrm{C}_{6} \mathrm{H}_{4}-\mathrm{CO}_{2}$ & D4MOP; PC; 266 & 532 & 18.4 & 1.05 & 10.91 & 40.0 & 40.0 & 8 & 21 \\
\hline $1-\mathrm{Nph}-\mathrm{CO}_{2}$ & D1NPO; PC; 266 & 390 & 15.9 & 1.04 & 9.20 & 41.7 & 41.7 & 8 & 19,21 \\
\hline $2-\mathrm{Me}-\mathrm{C}_{6} \mathrm{H}_{4}-\mathrm{CO}_{2}$ & D2MBP; PC; 266 & $330-40$ & 17.2 & $\begin{array}{l}1.05 \\
0.97^{a}\end{array}$ & $\begin{array}{l}8.70 \\
7.19^{a}\end{array}$ & 40.6 & 40.6 & 10 & This work \\
\hline $\mathrm{Ph}-\mathrm{CO}_{2}$ & TBPB; $n-\mathrm{C}_{7} \mathrm{H}_{16} ; 282$ & 600 & 19.5 & 1.06 & 8.95 & 38.4 & 33.2 & 8 & 17 \\
\hline $\mathrm{Ph}-\mathrm{CO}_{2}$ & DBPO; $\mathrm{CHCl}_{3} ; 266$ & 700 & 19.0 & 1.06 & 8.95 & 38.6 & 30.9 & 8 & 17 \\
\hline $\mathrm{Ph}-\mathrm{O}-\mathrm{CO}_{2}$ & ТВРPC $; n-\mathrm{C}_{7} \mathrm{H}_{16} ; 257$ & 600 & 22.7 & 1.04 & 4.29 & 41.7 & 20.3 & 8 & 20,46 \\
\hline $\mathrm{Ph}-\mathrm{CH}_{2}-\mathrm{CO}_{2}$ & ТВРPA; PC; 266 & 766 & 24.3 & 1.02 & 3.32 & 42.9 & 8.6 & 8 & 20,46 \\
\hline 2-Nph-O- $\mathrm{CO}_{2}$ & TBNC; $n-\mathrm{C}_{7} \mathrm{H}_{16} ; 282$ & 600 & 19.4 & 1.00 & 2.86 & 49.5 & 7.7 & 8 & $20,21,46$ \\
\hline
\end{tabular}
Section III for details) 
saddle point geometries are quite different from the corresponding reactant structures (see Table 2). Whereas these systems are planar in both the reactant and the transition states, the carbonyloxy species with substituents in orthoposition, 2-Me- $\mathrm{C}_{6} \mathrm{H}_{4}-\mathrm{CO}_{2}, 2,4-\mathrm{Cl}_{2}-\mathrm{C}_{6} \mathrm{H}_{3}-\mathrm{CO}_{2}$ and 1-Nph$\mathrm{CO}_{2}$ (group 2), exhibit twisted carboxyl groups at the saddle points pertinent to decarboxylation.

With the carbonyloxy radicals in which a bridging atom or group separates the $\mathrm{CO}_{2}$ moiety from the aromatic chromophore, $\mathrm{Ph}-\mathrm{O}-\mathrm{CO}_{2}, \mathrm{Ph}-\mathrm{CH}_{2}-\mathrm{CO}_{2}$ and 2-Nph-O- $\mathrm{CO}_{2}$ (group $3)^{20,46}$, the flatness of the PESs with respect to several nuclear displacements renders the localization of saddle points much more difficult. ${ }^{46}$ The barrier to decarboxylation is decreased by almost one order of magnitude as compared to the group 1 and 2 species (Table 4). On the other hand, the reaction enthalpies are highly negative, with exothermicities of $30 \mathrm{kcal} \mathrm{mol}^{-1}$ (Table 4). The transition state structures are quite close to those of the reactant species. The low barriers correlate with the characterization of the saddle points of the bridged systems as 'early' transition states.

Group 1. The benzoyloxy radical exhibits $C_{2 \mathrm{v}}$ symmetry whereas 4- $\mathrm{Me}-\mathrm{C}_{6} \mathrm{H}_{4}-\mathrm{CO}_{2}$ and $4-\mathrm{MeO}-\mathrm{C}_{6} \mathrm{H}_{4}-\mathrm{CO}_{2}$ are only of $\mathrm{C}_{\mathrm{s}}$ symmetry (with a symmetry plane perpendicular and parallel to the ring plane, respectively). Identical symmetries are found for the associated transition states. The geometric parameters are reported in Table 2. The $\mathrm{O}-\mathrm{C}-\mathrm{O}$ angles were estimated to be in the range 110 to $112^{\circ}$ for the reactant states and between 149 and $151^{\circ}$ in the transition states. The breaking $\mathrm{C}-\mathrm{C}$ bond stretches from values between 1.46 and $1.47 \AA$ to values between 1.88 and $1.92 \AA$ in the transition state, whereas the $\mathrm{C}-\mathrm{O}$ bond lengths decrease (on average) from 1.26 to $1.20 \AA$. The imaginary wavenumbers of the transition modes are relatively similar: $253 i \mathrm{~cm}^{-1}\left(\mathrm{Ph}-\mathrm{CO}_{2}\right), 260 i \mathrm{~cm}^{-1}$ $\left(4-\mathrm{Me}-\mathrm{C}_{6} \mathrm{H}_{4}-\mathrm{CO}_{2}\right), \quad 274 i \quad \mathrm{~cm}^{-1}$ (4- $\left.\mathrm{MeO}-\mathrm{C}_{6} \mathrm{H}_{4}-\mathrm{CO}_{2}\right)$, and $250 i \mathrm{~cm}^{-1}\left(2-\mathrm{Nph}-\mathrm{CO}_{2}\right)$. The curvatures at the top of the barriers differ because of the influence of the disparate reduced masses.

The energetics of the group 1 compounds are contained in Table 3. The barrier height at the highest level of theory, UB3LYP/6-311+G(2df,2pd)//UB3LYP/6-311+G(d,p), amounts to $8.4 \mathrm{kcal} \mathrm{mol}^{-1}$ for benzoyloxy and is slightly higher, by 1.0 and $2.0 \mathrm{kcal} \mathrm{mol}^{-1}$, in case of methyl and methoxy substitution in para position, respectively. Simultaneously, these substituents turn the reaction less exothermic, by 1.3 and $3.2 \mathrm{kcal} \mathrm{mol}^{-1}$, respectively. This result is fully consistent with the Bell-Evans-Polanyi prediction of higher exothermicities being associated with smaller barriers and vice versa. ${ }^{47}$ The exocyclic substituents push electrons in the ring systems with the mesomeric $+\mathrm{M}$ effect of the methoxy group being slightly stronger than the purely inductive $+\mathrm{I}$ (or hyperconjugation) effect of the methyl group. The electronic effects stabilize reactants to a larger extent than transition states because the mesomeric structure on the right hand side in Scheme 3 is less important for the strongly elongated bond situation at the saddle points. The barrier for $2-\mathrm{Nph}-\mathrm{CO}_{2}$ is 0.5 $\mathrm{kcal} \mathrm{mol}{ }^{-1}$ above the one for benzoyloxy due to enhanced electron delocalization which stabilizes the reactant to a larger extent than the transition state.

The barriers for internal rotations of the $\mathrm{CO}_{2}$ moiety around the $\mathrm{C}-\mathrm{C}$ bond to be broken are similar in benzoyloxy, 4-Me$\mathrm{C}_{6} \mathrm{H}_{4}-\mathrm{CO}_{2}$, and 2-Nph- $\mathrm{CO}_{2}$ and are clearly above the values estimated for 4-MeO- $\mathrm{C}_{6} \mathrm{H}_{4}-\mathrm{CO}_{2}$ and 1-Nph- $-\mathrm{CO}_{2}$ (Table 3). It should be noted that internal rotation and thus breaking of symmetry may occur already at energies far below the reaction threshold.

Group 2. Carbonyloxy radicals with substituents in orthoposition have reactant geometries which are very similar to those of the group 1 species (see Table 2). The saddle point

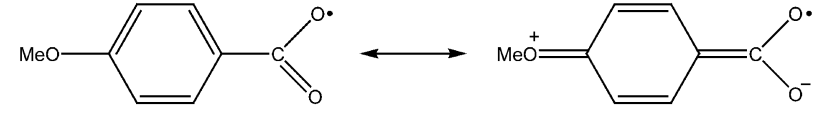

Scheme 3 Mesomeric structures of the 4-methoxy-benzoyloxy radical

structures, however, show twisted carboxyl groups. The $\mathrm{C}-\mathrm{CO}_{2}$ distances are slightly longer which goes along with a reduction in double bond character. The dihedral angle $\mathrm{O}-\mathrm{C}-\mathrm{C}_{\text {ring }}-\mathrm{C}_{\text {ring, } \alpha}$ (where the $\mathrm{O}$ atom is the one that is located close to the ortho-substituent) which is $180^{\circ}$ in the reactant (in trans conformation) is reduced to $81^{\circ}\left(2,4-\mathrm{Cl}_{2}-\mathrm{C}_{6} \mathrm{H}_{3}-\mathrm{CO}_{2}\right), 55^{\circ}$ $\left(2-\mathrm{Me}-\mathrm{C}_{6} \mathrm{H}_{4}-\mathrm{CO}_{2}\right)$ and $47^{\circ}\left(1-\mathrm{Nph}-\mathrm{CO}_{2}\right)$ in the transition structures, whereas the $\mathrm{C}-\mathrm{CO}_{2}$ distances, on average, are only slightly longer $(0.05 \AA)$ and the $\mathrm{O}-\mathrm{C}-\mathrm{O}$ angles slightly wider than in the para-substituted or unsubstituted (group 1) compounds. The imaginary wavenumber of the transition mode is relatively similar to the group 1 species for $2-\mathrm{Me}-\mathrm{C}_{6} \mathrm{H}_{4}-\mathrm{CO}_{2}$ $\left(279 i \mathrm{~cm}^{-1}\right)$, but is considerably higher for $1-\mathrm{Nph}-\mathrm{CO}_{2}(345 i$ $\mathrm{cm}^{-1}$ ) and $2,4-\mathrm{Cl}_{2}-\mathrm{C}_{6} \mathrm{H}_{3}-\mathrm{CO}_{2}\left(419 i \mathrm{~cm}^{-1}\right)$.

The energetics of the decarboxylations shows an increase in the barrier height for the 2,4-Cl substituted system, almost as high as observed for the para-methoxy substituted ring (group 1). This clearly shows that, in the language of organic chemistry, the $+\mathrm{M}$ effect is more important than the $-\mathrm{I}$ effect for chlorine substituents, as observed, e.g., in electrophilic substitution at aromatic rings. The 2-methyl substituted system, on the contrary, shows a barrier height to decarboxylation which is not only smaller as compared to the isomeric parasubstituted species (2-Me- $\left.\mathrm{C}_{6} \mathrm{H}_{4}-\mathrm{CO}_{2}\right)$, but which is even smaller than for the unsubstituted phenyl carbonyloxy radical $\mathrm{Ph}-\mathrm{CO}_{2}$. This is explained by a less stable situation in the reactant molecule that is due to steric interaction between the hydrogen atoms of the substituent and the nearest oxygen atom of the carbonyloxy group.

The rotational barriers for the group 2 species are smaller than for group 1 species. This may be attributed to steric hindrance by the ortho-substituents which render the reactants less stable compared to the saddle points for internal rotation. This implies that the $+\mathrm{M}$ effect of chlorine not only overcompensates the $-\mathrm{I}$ effect but also the steric influence of the substituent in ortho-position.

The barrier for 1-Nph- $\mathrm{CO}_{2}$ is calculated to be slightly lower than for 2-Nph- $-\mathrm{CO}_{2}$. This finding may be explained by the saddle point structure of $1-\mathrm{Nph}-\mathrm{CO}_{2}$ which shows a larger $\mathrm{C}-$ $\mathrm{C}$ distance and a twisted $\mathrm{CO}_{2}$ group. These effects are associated with a decrease in the double-bond character of the bond to be broken.

For 2-Me- $\mathrm{C}_{6} \mathrm{H}_{4}-\mathrm{CO}_{2}$, a second unimolecular reaction channel may become important which has a barrier of $11.1 \mathrm{kcal}$ $\mathrm{mol}^{-1}$ and thus is only slightly above the classical threshold to decarboxylation. Here, a hydrogen atom is transferred from the methyl group to one of the oxygen atoms. The transition state (Fig. 7) shows a bicyclic structure. The six-membered ring has a $\mathrm{C}-\mathrm{H}-\mathrm{O}$ angle of $153.8^{\circ}$. The $\mathrm{C}-\mathrm{H}$ distance is $1.267 \AA$ and the $\mathrm{O}-\mathrm{H}$ distance measures $1.256 \AA$. The vibrational wavenumber of the transition mode is $1462 i \mathrm{~cm}^{-1}$. Owing to this

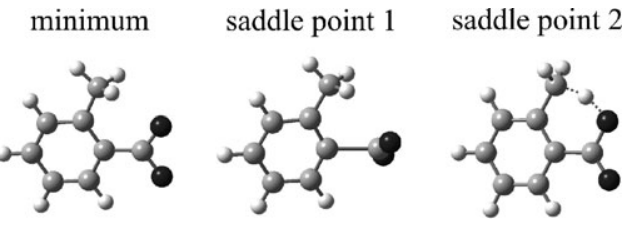

Fig. 7 Calculated geometries of the 2-Me- $\mathrm{C}_{6} \mathrm{H}_{4}-\mathrm{CO}_{2}$ radical and the saddle points pertinent to decarboxylation (saddle point 1) and isomerization (saddle point 2); UB3LYP/6-311+G(d,p) results. 
large number (which is typical for hydrogen migrations), the zero-point vibrational energy (at the harmonic level) is considerably smaller at this saddle point than the one for decarboxylation. As a consequence, the adiabatic barrier for isomerization $\left(E_{0}=7.6 \mathrm{kcal} \mathrm{mol}^{-1}\right)$ is below the one for decarboxylation $\left(E_{0}=8.2 \mathrm{kcal} \mathrm{mol}^{-1}\right){ }^{48}$

Group 3. Summarized in Table 4 are the barrier heights and enthalpies for decarboxylation of the bridged systems that were discussed in detail in ref. 46. The singly occupied molecular orbitals (SOMOs) of the product radicals from decarboxylation are perpendicular to the ring plane ( $\pi$-type) and thus participate in the conjugated electron system giving rise to the strong stabilization of these radicals and the high exothermicities upon decarboxylation. Whereas with the group 1 and 2 carbonyloxy radicals the breaking bond was stretched by more than $0.4 \AA$ in going from the reactant to the saddle point species, the elongation estimated for the bridged radicals amounts only to about $0.05 \AA$ (see Table 2). The associated small barriers to decarboxylation are not easily calculated, because the potential energy surfaces in the vicinity of the saddle points are extremely flat for numerous coordinates. The extremely low barrier in the case of $2-\mathrm{Nph}-\mathrm{O}-\mathrm{CO}_{2}$ becomes even negative when zero-point vibrational effects are taken into account. Absolute barrier heights which are in the range of the expected uncertainty of $1 \mathrm{kcal} \mathrm{mol}^{-1}$ certainly can not be accurately estimated from the DFT calculations. However, the relative size of the calculated barriers should be reliable as is confirmed by comparison with experimental data (see below).

\section{B. Sub-picosecond transient absorption spectroscopy}

As an example, results from femtosecond UV-VIS pumpprobe measurements on the diaroyl peroxide D4BMP are shown in Fig. 8, which are very similar to the ones measured for other diaroyl peroxides. An initial rise in absorbance $(\Delta \mathrm{OD})$ within the time-resolution of the experiment of $c a$. $200 \mathrm{fs}$ which is assigned to the formation of the intermediate 4-methyl benzoyloxy radical, is followed by a subsequent decay on a ps time-scale throughout the investigated UV-VIS spectral range. It is attributed to the fast decarboxylation and simultaneous vibrational cooling of initially "hot" intermediate 4-methyl benzoyloxy radicals. After vibrational relaxation is complete, the radicals decompose thermally on a much longer time-scale, which manifests itself as an "offset" of the decay traces.

Two transient absorption bands in the UV and VIS region (Fig. 8) may be assigned by comparison with the transient nanosecond spectrum of the 4-methyl benzoyloxy radical reported by Chateauneuf et al. ${ }^{14}$ As absorption due to the 4methyl phenyl product radical is expected to be very weak in the 300 to $740 \mathrm{~nm}$ spectral range, the decarboxylation kinetics of intermediate radicals in the decomposition of D4MBP may be directly deduced from the curves displayed in Fig. 8. No significant wavelength dependence of the absorbance decay is found, as illustrated in Fig. 9. It should be noted that the initial wavelength-dependent signal peak contains contributions from coherent solvent response. These peaks around zero time delay will be neglected in the analysis of the decay curves.

Experimental decay curves similar to those shown in Fig. 8 were obtained for the diaroyl peroxides D2MBP, DCBPO and D2NPO using UV pump/UV-VIS probe spectroscopy. Transient absorbance traces measured at different probe wavelengths in the range between $300-800 \mathrm{~nm}$ can be found in the ESI. $\dagger$ Again, no strong wavelength dependence of the decay curves was observed.

Whereas the formation and decarboxylation of carbonyloxy radicals after photo-induced decomposition of the organic
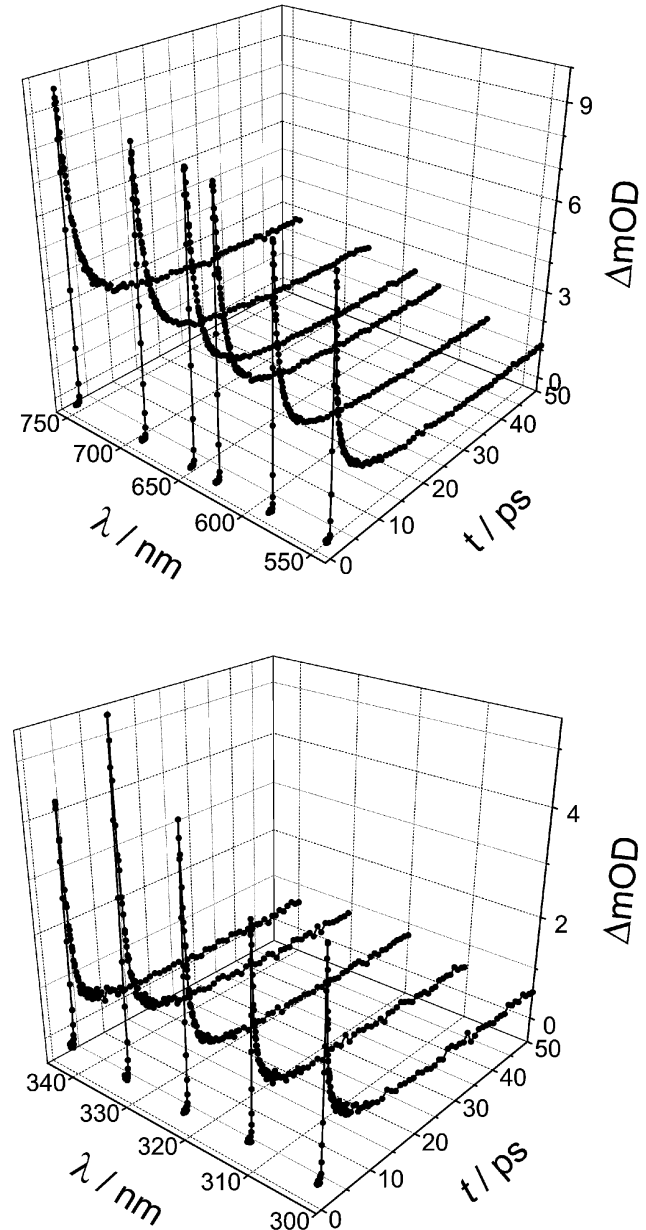

Fig. 8 Transient absorbance traces, $\Delta \mathrm{OD}$, of $4-\mathrm{Me}-\mathrm{C}_{6} \mathrm{H}_{4}-\mathrm{CO}_{2}$ radicals in propylene carbonate after excitation of D4MBP at $266 \mathrm{~nm}$.

peroxides was monitored in the VIS region, the formation of the $\mathrm{CO}_{2}$ product molecule was measured via its asymmetric stretching $\nu_{3}$ band in the IR. ${ }^{4}$ As an example, the transient IR absorption measured after picosecond photo-excitation of DBPO in $\mathrm{CH}_{2} \mathrm{Cl}_{2}$ at delay times $t$ up to $500 \mathrm{ps}$ is shown in Fig. 10. The decay curves were measured at $20 \mathrm{~cm}^{-1}$ intervals across the $\nu_{3}$-band of $\mathrm{CO}_{2}$. At $t=0$, an instantaneous rise in absorbance from a noise level of about $\Delta \mathrm{OD}= \pm 0.001$ is observed throughout the wavenumber range 2200 to 2350 $\mathrm{cm}^{-1}$. Toward longer delay times, due to vibrational cooling of nascent "hot" $\mathrm{CO}_{2}$, the absorption band simultaneously narrows and shifts to higher wavenumbers, resulting in a decrease of the absorbance at $2250 \mathrm{~cm}^{-1}$ and an increase at $2330 \mathrm{~cm}^{-1}$, as is illustrated in the lower part of Fig. 10. As we

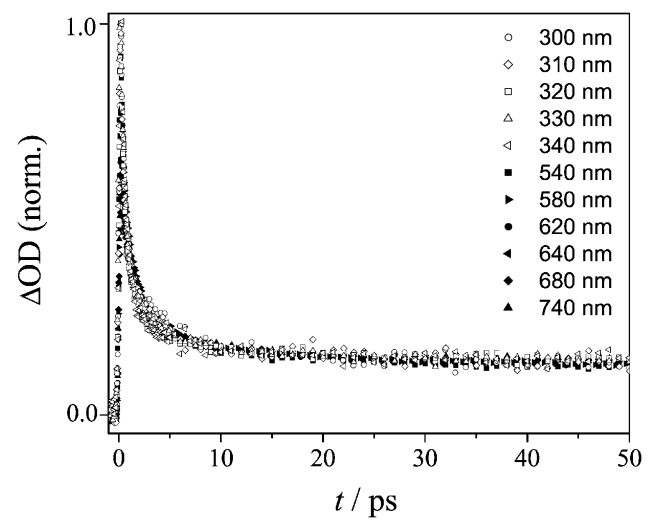

Fig. 9 Superposition of normalized transient absorbance decays of the $4-\mathrm{Me}-\mathrm{C}_{6} \mathrm{H}_{4}-\mathrm{CO}_{2}$ radical at different probe wavelengths. 


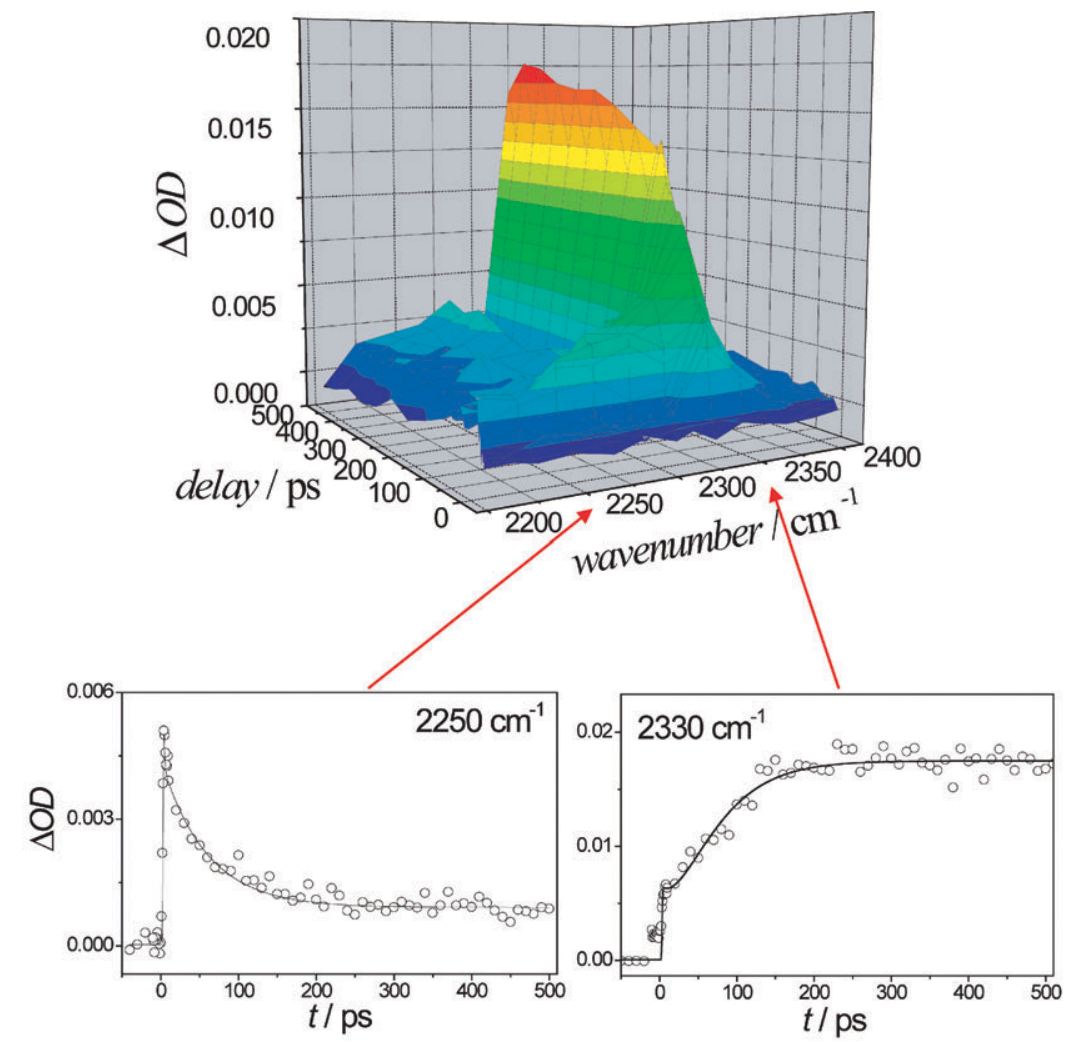

Fig. 10 Three-dimensional representation of the temporal and spectral evolution of the $\nu_{3}$ transient absorbance of $\mathrm{CO}_{2}$ (upper graph) and selected traces at 2250 and $2330 \mathrm{~cm}^{-1}$ after photolysis of DBPO at $248.5 \mathrm{~nm} \mathrm{in} \mathrm{CH}_{2} \mathrm{Cl}_{2}$ solution.

discussed in detail elsewhere, ${ }^{4,22,23}$ the time evolution of the spectral band shape reflects vibrational cooling of the initially vibrationally excited $\mathrm{CO}_{2}$ generated during the fragmentation of the aroyloxy radical. It appears that the initial red shift and broadening of the $\nu_{3}$-band is caused by population of higher vibrational levels of the symmetric stretch and degenerate bend modes, while the asymmetric stretch itself remains unexcited. $^{4,51}$ Molecular dynamics modeling of the band shape results in a vibrational temperature of these modes that tends to be higher than the initial temperature of the fragmenting radical. This observation is related to partitioning of the excess energy released in the exothermic decarboxylation between $\mathrm{CO}_{2}$ and the final product radical, which however does not affect our model description of the unimolecular dissociation reaction.

Taking the integral $\nu_{3}$-band absorbance as an approximately temperature-independent measure of the total $\mathrm{CO}_{2}$ concentration, ${ }^{4,22,23}$ its time evolution may be directly compared with that of the optical density at $700 \mathrm{~nm}$ due to benzoyloxy radicals after photodissociation of DBPO in $\mathrm{CH}_{2} \mathrm{Cl}_{2}$ at $266 \mathrm{~nm}$ (Fig. 11). (The latter curve was inverted for better comparison.) $\mathrm{CO}_{2}$ absorbance is affected by larger uncertainties within the first 10 to 15 ps due to background subtraction which limits the time resolution of the IR experiment to a few ps. ${ }^{4}$ Nevertheless, the close agreement of the time evolution of the two species derived from completely independent experiments is satisfying. Also the kinetics of $\mathrm{CO}_{2}$ formation during the photodissociation of the diaroyl peroxides D4MOP, D2NPO and D1NPO was found to occur in close agreement with the decay kinetics of the corresponding carbonyloxy radicals deduced from timeresolved UV-VIS spectroscopy.

In the case of TBNC photodissociation, it was possible to monitor in different spectral regions the transient absorbance of the three main species involved in the decarboxylation, i.e. the intermediate 2-naphthyloxycarbonyloxy radical as well as $\mathrm{CO}_{2}$ and the naphthyloxy radical, ${ }^{20,22}$ as illustrated in Fig. 12. Independent measurements of the formation of the 2-Nph-O radical and of $\mathrm{CO}_{2}$ and of the decay of the inter- mediate 2-Nph-O- $\mathrm{CO}_{2}$ radical gave identical results with respect to the decarboxylation kinetics of $2-\mathrm{Nph}-\mathrm{O}-\mathrm{CO}_{2}$ radicals generated in the photolysis of TBNC.

In general, for all systems studied, a spectral region could be identified where the transient absorbance could exclusively or at least predominantly be assigned to the corresponding intermediate radical. The corresponding probe wavelengths are given in Table 5. A slight wavelength dependence of the transient absorbance decays may arise from vibrational cooling that causes absorption bands to narrow on a picosecond time scale. This effect is practically negligible in the vicinity of the half maximum of the corresponding absorption band, where the extinction coefficient only changes marginally with internal energy. In most cases, the wavelength dependence was sufficiently small (see Fig. 9 for $4-\mathrm{Me}-\mathrm{C}_{6} \mathrm{H}_{4}-\mathrm{CO}_{2}$ and the electronic supplementary information (ESI) $\dagger$ ), such that transient absorbance traces taken anywhere in the UV-VIS spectral observation window of the radical were suitable for analysis of the intermediate radical decay.

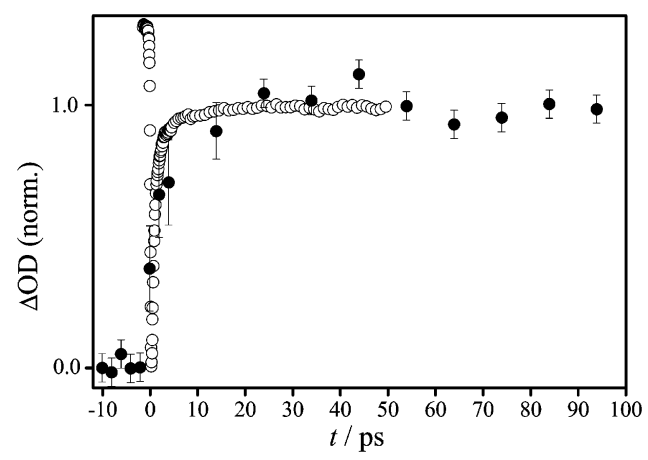

Fig. 11 Transient absorbance traces of the benzoyloxy radical and of $\mathrm{CO}_{2}$ following photolysis of DBPO in dichloromethane solution. $\bigcirc$ : Normalized and inverted transient absorbance of benzoyloxy radicals at $700 \mathrm{~nm}$ (photolysis at $266 \mathrm{~nm}$ ). ${ }^{17} \bullet: \mathrm{CO}_{2}$ integral $\nu_{3}$-band transient absorbance at $4.3 \mu \mathrm{m}$ (photolysis at $248.5 \mathrm{~nm}$ ). ${ }^{4}$ 


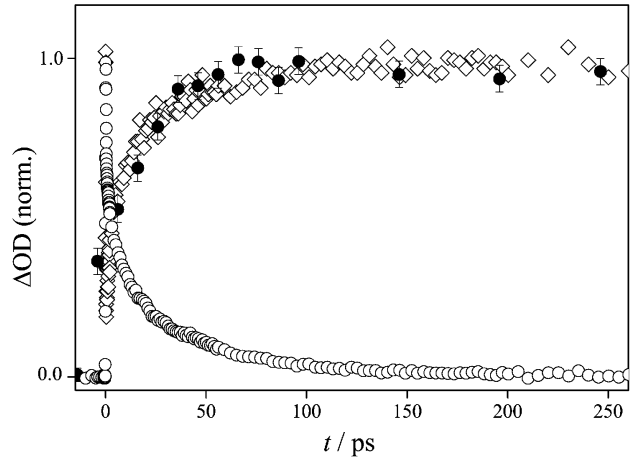

Fig. 12 Decay of 2-Nph-O- $\mathrm{CO}_{2}$ radical absorbance superimposed onto the absorbance rise due to formation of 2-Nph-O radicals and of $\mathrm{CO}_{2}$. 2-Nph-O-CO $\mathrm{CO}_{2}$ radical absorption was probed at $594 \mathrm{~nm}(\mathrm{O})$, and the 2-Nph-O radical was monitored at $297 \mathrm{~nm}(\diamond) . \mathrm{CO}_{2}$ formation (-) was obtained from the integrated transient absorbance at $4.3 \mu \mathrm{m}^{20,22}$

\section{Discussion}

Based on the assignment of measured transient absorbance decays to the carbonyloxy radical intermediate we can apply the model described in Section III to simulate the decarboxylation reaction. In a first step, we take our calculated carbonyloxy radical normal mode frequencies and decarboxylation barriers to compute room temperature thermal decarboxylation rate coefficients using eqns. (6) and (7). The barrier heights are slightly adjusted such that the calculated rate constants agree with the literature values listed in Table 1. As some carbonyloxy radicals decarboxylate more slowly in polar solvents than in non-polar solution, ${ }^{10,12,13}$ we take, where necessary, an average value of thermal rate constants measured in different solvents. Harmonic vibrational frequencies either are already published ${ }^{17,19-21,46}$ or can be found in the electronic supplementary information (ESI). Optimized barrier heights and rotational correction factors are given in Table 5. In a second step, we then apply the model to simulate decarboxylation and vibrational cooling of the nascent hot radicals. Adjustable parameter is the initial internal energy, $E_{\text {int }}(t=0)$, of the carbonyloxy radical after ultrafast photodissociation of the peroxide, at a fixed value of the vibrational relaxation time $\tau_{\mathrm{VET}}=(8 \pm 2)$ ps (see Section III).

Fig. 13 illustrates the kind of agreement achieved between measurement and model simulation for the radicals $4-\mathrm{Me}$ $\mathrm{C}_{6} \mathrm{H}_{4}-\mathrm{CO}_{2}, 2,4-\mathrm{Cl}_{2}-\mathrm{C}_{6} \mathrm{H}_{3}-\mathrm{CO}_{2}$, and 2-Nph- $\mathrm{CO}_{2}$ (parameter values are listed in Table 5). Whereas thermal decarboxylation rate constants and corresponding activation energies of 4-Me$\mathrm{C}_{6} \mathrm{H}_{4}-\mathrm{CO}_{2}$ and 2-Nph- $\mathrm{CO}_{2}$ are known (see Table 1), no values have been reported for the $2,4-\mathrm{Cl}_{2}-\mathrm{C}_{6} \mathrm{H}_{3}-\mathrm{CO}_{2}$ radical. Literature values of rate constants for mono-chloro substituted benzoyloxy radicals at ambient temperature are between $1.3 \times$ $10^{6}$ and $1.9 \times 10^{6} \mathrm{~s}^{-1}$ for $2-\mathrm{Cl}-\mathrm{C}_{6} \mathrm{H}_{4}-\mathrm{CO}_{2}^{49}$ and $4-\mathrm{Cl}-\mathrm{C}_{6} \mathrm{H}_{4}-$ $\mathrm{CO}_{2}^{11,13}$ radicals and between $10 \times 10^{6}$ and $17 \times 10^{6} \mathrm{~s}^{-1}$ for 2,6- $-\mathrm{Cl}_{2}-\mathrm{C}_{6} \mathrm{H}_{3}-\mathrm{CO}_{2}{ }^{10,49}$ If we assume that the thermal decarboxylation rate constant of $2,4-\mathrm{Cl}_{2}-\mathrm{C}_{6} \mathrm{H}_{3}-\mathrm{CO}_{2}$ is close to the mean value of rate constants reported for the meta- and parasubstituted monochloro-benzoyloxy radicals, i.e. $\sim 1.5 \times 10^{6}$ $\mathrm{s}^{-1}$ at $298 \mathrm{~K}$, we obtain a barrier height of $9.89 \mathrm{kcal} \mathrm{mol}^{-1}$ (Table 5), which is in very good agreement with our calculated value of $10.1 \mathrm{kcal} \mathrm{mol}^{-1}$ (Table 3).

The situation is more complex for the $2-\mathrm{Me}-\mathrm{C}_{6} \mathrm{H}_{4}-\mathrm{CO}_{2}$ radical as illustrated in Fig. 14, which shows the transient absorbance decay probed at $340 \mathrm{~nm}$ after $266 \mathrm{~nm}$ photolysis of D2MBP in propylene carbonate. The dotted line represents the model simulation for 2-Me- $\mathrm{C}_{6} \mathrm{H}_{4}-\mathrm{CO}_{2}$ ground state decarboxylation with the highest barrier $\left(8.70 \mathrm{kcal} \mathrm{mol}^{-1}\right)$ obtained from DFT calculations (Table 3). Even with this value, the decay rate of $2-\mathrm{Me}-\mathrm{C}_{6} \mathrm{H}_{4}-\mathrm{CO}_{2}$ radicals is overestimated by the

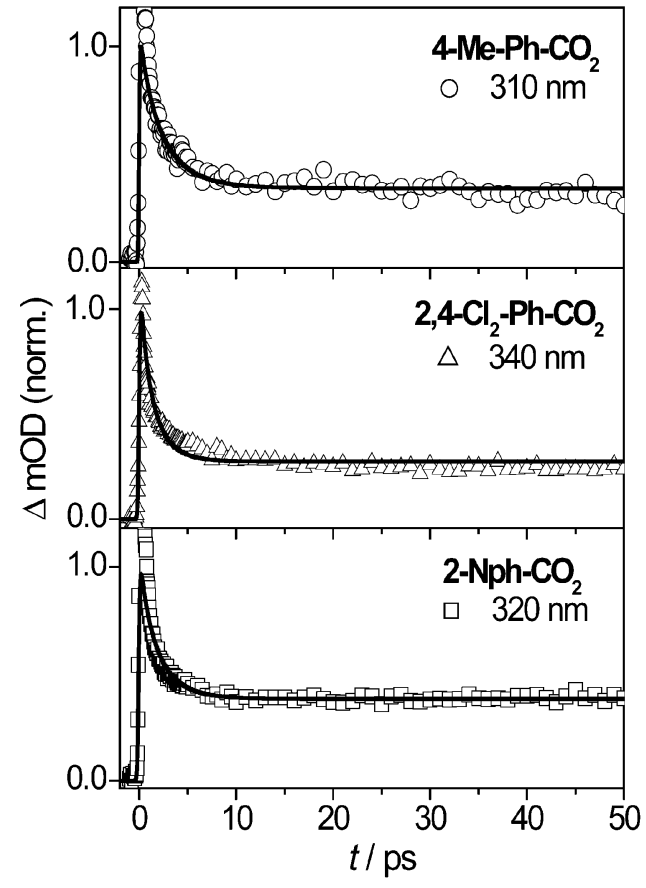

Fig. 13 Transient absorbance decays of 4- $\mathrm{Me}-\mathrm{C}_{6} \mathrm{H}_{4}-\mathrm{CO}_{2}, 2,4-\mathrm{Cl}_{2}-$ $\mathrm{C}_{6} \mathrm{H}_{3}-\mathrm{CO}_{2}$, and $2-\mathrm{Nph}-\mathrm{CO}_{2}$ radicals from the decomposition of the corresponding diaroyl peroxides in propylene carbonate solution. Lines represent model simulations as described in the text (model parameters are given in Table 5).

simulation. However, as we discussed in Section IVA, intramolecular hydrogen atom migration may occur in $2-\mathrm{Me}-\mathrm{C}_{6} \mathrm{H}_{4}$ $-\mathrm{CO}_{2}$ and compete with decarboxylation. The dashed line shows a simulation of intramolecular hydrogen atom transfer with a barrier of $E_{0}=7.19 \mathrm{kcal} \mathrm{mol}^{-1}$ as deduced from the thermal lifetime of $2-\mathrm{Me}-\mathrm{C}_{6} \mathrm{H}_{4}-\mathrm{CO}_{2}$ radicals at ambient temperature (Table 1). ${ }^{50}$ This clearly underestimates the decay rate of $2-\mathrm{Me}-\mathrm{C}_{6} \mathrm{H}_{4}-\mathrm{CO}_{2}$ radicals.

This observation appears surprising at first glance, since hydrogen atom migration is faster than decarboxylation at thermal energies associated with ambient temperature. The situation is different, however, for the decomposition of vibrationally hot 2-Me- $\mathrm{C}_{6} \mathrm{H}_{4}-\mathrm{CO}_{2}$ radicals at internal energies up to $E_{\text {ava }}=40.6 \mathrm{kcal} \mathrm{mol}^{-1}$ (following photolysis of D2MBP at $266 \mathrm{~nm}$ ). Due to different transition modes and, consequently, markedly different energy dependences of microcanonical rate constants, $k(E)$, for decarboxylation and hydrogen migration, decarboxylation at higher energies becomes faster than

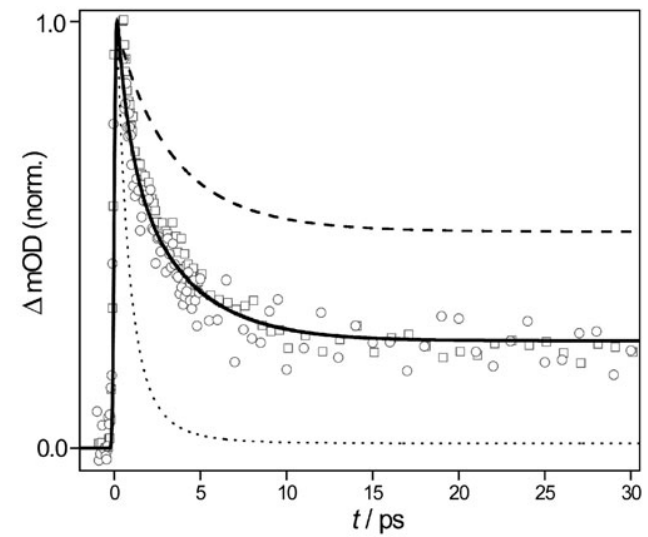

Fig. 14 Transient absorbance decays of 2-Me- $\mathrm{C}_{6} \mathrm{H}_{4}-\mathrm{CO}_{2}$ radicals at $330(\square)$ and $340 \mathrm{~nm}(\bigcirc)$ after photolysis of D2MBP at $266 \mathrm{~nm}$. Lines represent model simulations: intramolecular hydrogen transfer (dashed), decarboxylation (dotted) and 60\% hydrogen transfer + $40 \%$ decarboxylation (solid). For further details see the text. 
hydrogen migration. Agreement between simulation and measurement is achieved by taking into account both competing reaction channels with a branching ratio of three to two in favour of hydrogen atom migration versus decarboxylation (solid line in Fig. 14). The branching ratio strongly depends on the barrier heights for both reactions. The decarboxylation barrier is calculated at the UB3LYP/6-311+G(2d,p) level of theory (Table 3), as for several carbonyloxy radicals. Close agreement was found between calculated and optimized reaction barriers. ${ }^{19}$ The barrier for hydrogen migration, on the other hand, is consistent with the reported thermal lifetime of 2- $\mathrm{Me}-\mathrm{C}_{6} \mathrm{H}_{4}-\mathrm{CO}_{2}$ radicals ${ }^{50}$ and also in excellent agreement with the calculated reaction barrier (see Section IVA). Taking into account the uncertainty in the barrier heights for both reactions, we estimate the branching ratio to be accurate to within $\pm 20 \%$. Using the information from modeling the photo-induced radical decomposition one may quantitatively describe the kinetics of the individual thermally activated reaction channels. For this purpose, an Arrhenius expression, $k(T)=A \exp \left(-E_{\mathrm{a}} / R T\right)$, is fitted to thermal rate constants calculated from statistical rate theory for the temperature range from 200 to $2000 \mathrm{~K}$. The resulting pre-exponential factors and activation energies for both reaction channels of the $2-\mathrm{Me}-\mathrm{C}_{6} \mathrm{H}_{4}-\mathrm{CO}_{2}$ radical are $A=8.7 \times 10^{12} \mathrm{~s}^{-1}$ and $E_{\mathrm{a}}=$ $7.8 \mathrm{kcal} \mathrm{mol}^{-1}$ for hydrogen-atom migration, and $A=2.0 \times$ $10^{14} \mathrm{~s}^{-1}$ and $E_{\mathrm{a}}=10.0 \mathrm{kcal} \mathrm{mol}^{-1}$ for decarboxylation.

Based on these results of modeling the thermal decarboxylation of the four carbonyloxy radicals $4-\mathrm{Me}-\mathrm{C}_{6} \mathrm{H}_{4}-\mathrm{CO}_{2}$, 2-Nph- $-\mathrm{CO}_{2}, 2,4-\mathrm{Cl}_{2}-\mathrm{C}_{6} \mathrm{H}_{3}-\mathrm{CO}_{2}$, and 2-Me- $\mathrm{C}_{6} \mathrm{H}_{4}-\mathrm{CO}_{2}$ at ambient temperature, the vibrational cooling and decomposition of the nascent vibrationally hot radicals in the picosecond domain can be simulated. In all four cases, the optimized initial internal energy $E_{\text {int }}(t=0)$ of these radicals is identical to the statistically calculated available energy $E_{\text {ava, }}$, which suggests that, according to our model, decarboxylation takes place exclusively on the ground state PES. The consistent description of the ground state fragmentation of these six radicals may also be taken as evidence that the fundamental assumptions of the statistical model, that IVR within the radical is at least close to complete prior to decarboxylation, seems to be justified as far as its relevance for the kinetics of the reaction is concerned. Of course, our model is not capable of resolving finer details of the dynamics, such as separating the contributions from IVR and collisional energy transfer to the vibrational energy relaxation of the hot radical, ${ }^{51}$ but this would be of no consequence here. It should be noted that the vibrational cooling time constant has to be varied between 6 and $10 \mathrm{ps}$ to correctly reproduce the contribution of "hot" versus room temperature reaction, (peak amplitude versus "offset" of the absorbance signal, see Section III). These variations in vibrational cooling rate with the type of carbonyloxy radical are rationalized on a quantitative basis in molecular dynamics simulations of vibration relaxation. ${ }^{18,42}$ Decarboxylation on the ground state PES was found to be the only reaction channel also for the radicals $4-\mathrm{MeO}-\mathrm{C}_{6} \mathrm{H}_{4}-\mathrm{CO}_{2}$ (from D4MOP photolysis at $266 \mathrm{~nm})^{21}$ and $1-\mathrm{Nph}-\mathrm{CO}_{2}$ (from D1NPO photolysis at $266 \mathrm{~nm}),{ }^{19,21}$ as may be inferred from a comparison of the corresponding values of $E_{\text {int }}(t=0)$ and $E_{\text {ava }}$ in Table 5 .

Quite to the contrary, the equivalent simulation of $\mathrm{Ph}-\mathrm{CO}_{2}$ decarboxylation generated by TBPB photolysis at $282 \mathrm{~nm}$ results in $E_{\text {int }}(t=0)=33.2 \mathrm{kcal} \mathrm{mol}^{-1}$ while $E_{\text {ava }}$ is estimated to be $38.4 \mathrm{kcal} \mathrm{mol}^{-1}$. As discussed in detail in Section III, this discrepancy may be understood as a consequence of direct decarboxylation via the ${ }^{2} \mathrm{~A}_{1}$ excited electronic state of $\mathrm{Ph}-\mathrm{CO}_{2}$. Naturally, only the high-energy radicals can take this route, which results in a truncation of the high-energy tail of the energy distribution of benzoyloxy radicals that are left to decarboxylate on the ground state potential energy surface. A similar type of behavior with instantaneous decarboxylation via an excited electronic state was found for the decarboxylation of benzoyloxy radicals from DBPO photolysis at 266 $\mathrm{nm} .{ }^{17}$ As the peroxy bond dissociation energy of TBPB and DBPO are different, the fraction of radicals undergoing decarboxylation via the excited state is not the same for these two parent molecules. The branching ratio between excited and ground state channel may be estimated from $\mathrm{CO}_{2}$ excess energies ${ }^{4}$ or from the values of $E_{\text {int }}(t=0)$ obtained from our model simulations. In this way, the contributions of the excited state channel to benzoyloxy radical decarboxylation after photolysis of TBPB at $282 \mathrm{~nm}$ and of DBPO at $266 \mathrm{~nm}$ may be roughly estimated as $(25 \pm 10) \%$ and $(50 \pm 20) \%$, respectively. ${ }^{43}$

It is interesting to note at this point that the decarboxylation barrier heights for aroyloxy radicals $\left(\mathrm{Ph}-\mathrm{CO}_{2}, 4-\mathrm{Me}-\mathrm{C}_{6} \mathrm{H}_{4}-\right.$ $\mathrm{CO}_{2}, \quad 4-\mathrm{MeO}-\mathrm{C}_{6} \mathrm{H}_{4}-\mathrm{CO}_{2}, \quad 2-\mathrm{Nph}-\mathrm{CO}_{2}, \quad 2,4-\mathrm{Cl}-\mathrm{C}_{6} \mathrm{H}_{4}-\mathrm{CO}_{2}$, $2-\mathrm{Me}-\mathrm{C}_{6} \mathrm{H}_{4}-\mathrm{CO}_{2}, 1-\mathrm{Nph}-\mathrm{CO}_{2}$ ) resulting from the model simulation of thermal decarboxylation rates (Table 5) within chemical accuracy agree with the values calculated by DFT methods (Table 3). In addition, trends in relative barrier heights are well reproduced. DFT should thus be favored over UHF methods ${ }^{15}$ for these systems.

The examples discussed so far show that substituents at the aromatic ring, with the exception of 2-alkyl moieties (see above), ${ }^{50}$ do not induce significant changes in decarboxylation behavior. The thermal reactions occur on nano- to microsecond time scales at ambient temperature and excited electronic state reaction channels do not play a significant role in aroyloxy radical decarboxylation, the single notable exception being $\mathrm{Ph}-\mathrm{CO}_{2}$. This partial lack of sensitivity of the kinetics toward chemical structure to some extent is at variance with expectations one might have had in view of the grouping based on our DFT calculations. Apparently, the slight differences in calculated transition state structural properties on the ground state surface between group 1 and 2 are not reflected in corresponding effects on the decarboxylation kinetics.

On the other hand, group 3 radicals, obtained by insertion of a $\mathrm{CH}_{2}$ group or of an oxygen atom between the aromatic ring system and the $\mathrm{CO}_{2}$ moiety $\left(\mathrm{R}-\mathrm{X}-\mathrm{CO}_{2}\right.$ systems, with $\mathrm{R}=$ phenyl, naphthyl; $\mathrm{X}=\mathrm{CH}_{2}, \mathrm{O}$ ), show a significantly different decarboxylation behavior. ${ }^{20,46} \mathrm{~A}$ characteristic feature of $\mathrm{R}-\mathrm{X}-\mathrm{CO}_{2}$ decarboxylation is the high exothermicity (see Table 4). According to the Bell-Evans-Polanyi principle, ${ }^{47}$ high reaction enthalpies are accompanied by rather low reaction barriers. Thermal rate constants or activation parameters for decarboxylation of $\mathrm{R}-\mathrm{X}-\mathrm{CO}_{2}$ radicals have not been reported so far. The relative sizes of barrier heights should be adequately predicted by our quantum-chemical calculations (Table 4), ${ }^{20,46}$ though accurate absolute values for such small barriers can hardly be expected from DFT calculations. The decarboxylation barriers thus were deduced from model simulations of the measured transient absorbance decays. The thermal decarboxylation of $\mathrm{R}-\mathrm{X}-\mathrm{CO}_{2}$ radicals occurs in the picosecond to nanosecond range even at ambient temperature and may be accurately measured in our experiments (Fig. 15). Whereas the transient absorbance decays show signatures of vibrationally excited species and multi-exponential decay at early times after photo-excitation, typically from delay times of about 20 ps onwards, single-exponential decays are observed (Fig. 15). This indicates that vibrational energy transfer is complete and that the long decay time constant represents the ambient temperature lifetime of the intermediate carbonyloxy radicals. The barriers extracted from the decays are summarized in Table 5, and the associated simulated signals are plotted in Fig. 15 as solid lines together with measured decays of the radicals $\mathrm{Ph}-\mathrm{O}-\mathrm{CO}_{2}, \mathrm{Ph}-\mathrm{CH}_{2}-\mathrm{CO}_{2}$, and 2-Nph$\mathrm{O}-\mathrm{CO}_{2}$. For all three systems, the optimized initial internal energy $E_{\text {int }}(t=0)$ is significantly lower than the available energy $E_{\text {ava }}$. The reaction rates increase in the order 


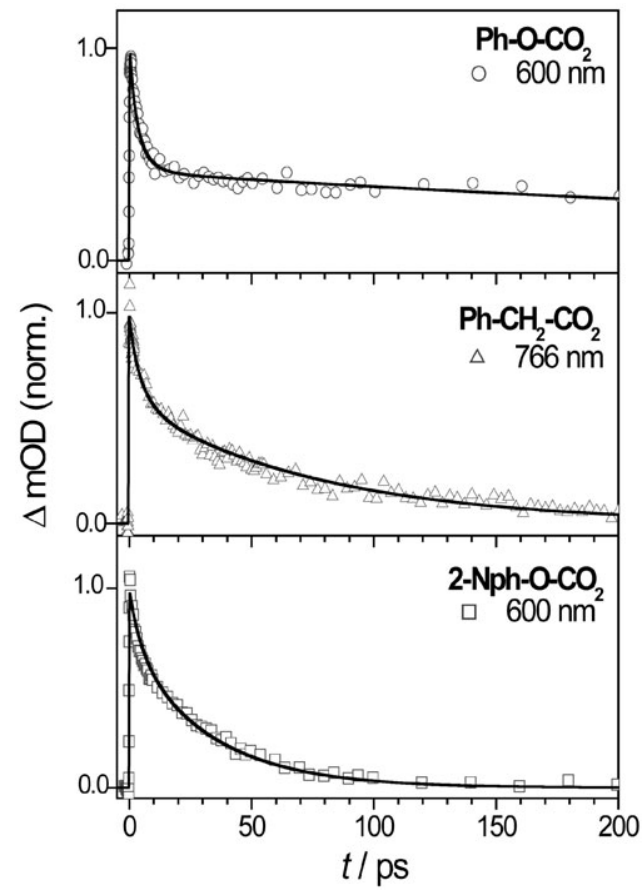

Fig. 15 Transient absorbance decays of $\mathrm{Ph}-\mathrm{O}-\mathrm{CO}_{2}$ in $n$-heptane, $\mathrm{Ph}$ $\mathrm{CH}_{2}-\mathrm{CO}_{2}$ in propylene carbonate, and 2-Nph-O- $\mathrm{CO}_{2}$ in $n$-heptane. ${ }^{20}$ Probe wavelengths are as indicated. Lines represent model simulations as described in the text (model parameters are given in Table 5).

$\mathrm{Ph}-\mathrm{O}-\mathrm{CO}_{2}<\mathrm{Ph}-\mathrm{CH}_{2}-\mathrm{CO}_{2}<2-\mathrm{Nph}-\mathrm{O}-\mathrm{CO}_{2}$, while values of $E_{\text {int }}(t=0)$ decrease at the same time.

As discussed in Section III, in the case of $\mathrm{Ph}-\mathrm{CO}_{2}$ the low value of $E_{\text {int }}(t=0)$ within the framework of our statistical model can be quantitatively accounted for by a large fraction $(50 \pm 20 \%)$ of ultrafast direct decarboxylation via an electronically excited state. We suspect, therefore, that a corresponding excited state channel also contributes significantly to the overall decarboxylation reaction for $\mathrm{Ph}-\mathrm{O}-\mathrm{CO}_{2}(50 \pm 20 \%)$, $\mathrm{Ph}-\mathrm{CH}_{2}-\mathrm{CO}_{2}(75 \pm 20 \%)$, and 2-Nph-O- $\mathrm{CO}_{2}(50 \pm 30 \%) .{ }^{20}$ In these cases, yields are based on product transient absorbance rise. The statistical model predicts even higher values $>90 \%$, which probably means that our approach reaches its limits for such low reaction barriers. In any case, low decarboxylation barrier heights of $\mathrm{R}-\mathrm{X}-\mathrm{CO}_{2}$ radicals seem to be associated with large direct excited state contributions, suggesting that the energy gap between ground and first electronically excited state is smaller for less stable carbonyloxy radicals.

\section{Conclusions}

Chemical intuition and experience have told polymer chemists for quite some time that organic peroxide decomposition kinetics and mechanism are linked to the structure of the parent peroxide and the stability of the corresponding radical intermediate. ${ }^{10}$ However, this dependence on structure has not been characterized in sufficient detail, and no quantitative model with predictive qualities has been suggested. Our systematic experimental and quantum-chemical investigation of a large family of organic peroxides enabled us to develop for the first time a relatively simple model based upon statistical rate theory and a phenomenological description of vibrational cooling. The model relies on input data from quantum-chemical calculations and thermochemistry to successfully describe all available carbonyloxy radical decarboxylation rates. At the same time, as we are convinced, it may be employed to predict in a semi-quantitative way both the photo-induced and the thermal decarboxylation of organic peroxides in general. It may help to find criteria to group them in families and to predict kinetics from ultrafast to "thermal" time-scales. The model should be useful for chemists who want to control the initial steps of light-induced polymerization, the initiator efficiency and the transfer activity of primary initiator-derived free radicals.

\section{Acknowledgements}

The authors acknowledge financial support from the Deutsche Forschungsgemeinschaft within the Sonderforschungsbereich 357 ("Molekulare Mechanismen Unimolekularer Prozesse"). We thank the "Fonds der Chemischen Industrie" for additional support, and we are grateful to AKZO Nobel Polymer Chemicals (Deventer) for providing the peroxide samples. Part of this work was carried out in close collaboration with Bernd Abel, whose contributions are gratefully acknowledged. We further thank Jens Aßmann, Christian Grimm, Rainer Oswald, Thomas Witte, and Jochen Zerbs for extensive help during various stages of this project. We also enjoyed stimulating discussions of central aspects of this work with Peter Botschwina, Dirk Schwarzer and Jürgen Troe.

\section{References}

1 (a) K. Fujimori, in Organic Peroxides, ed. W. Ando, Wiley, New York, 1992, p. 319; (b) C. A. Barson and J. C. Bevington, J. Polym. Sci. A: Polym. Chem., 1997, 35, 2955.

2 Y. Sawaki, in Organic Peroxides, ed. W. Ando, Wiley, New York, 1992, p. 425.

3 M. Buback and J. Sandmann, Z. Phys. Chem., 2000, 214, 583.

4 M. Buback, M. Kling, M. T. Seidel, F.-D. Schott, J. Schroeder and U. Steegmüller, Z. Phys. Chem., 2001, 215, 717.

5 M. Buback, M. Kling, D. Nelke, S. Schmatz and H.-P. Voegele, in preparation.

6 T. Nakamura, S. Suyama, W. K. Busfield, I. D. Jenkins, E. Rizzardo and S. H. Thang, Polymer, 1999, 40, 1395.

7 C. Maul and K.-H. Gericke, Int. Rev. Phys. Chem., 1997, 16, 1.

8 J. Chateauneuf, J. Lusztyk and K. U. Ingold, J. Am. Chem. Soc., 1988, 110, 2877.

9 (a) J. Hashimoto, K. Segawa and H. Sakuragi, Chem. Phys. Lett., 1999, 314, 261; (b) S. Yamauchi, N. Hirota, S. Takahara, H. Sakuragi and K. Tokumaru, J. Am. Chem. Soc., 1985, 107, 5021.

10 J. Wang, T. Tateno, H. Sakuragi and K. Tokumaru, J. Photochem. Photobiol., 1995, 92, 53.

11 S. Yamauchi, N. Hirota, S. Takahara, H. Misawa, K. Sawabe, H. Sakuragi and K. Tokumaru, J. Am. Chem. Soc., 1989, 111, 4402.

12 T. Tateno, H. Sakuragi and K. Tokumaru, Chem. Lett., 1992, 21, 1883.

13 H. Misawa, K. Sawabe, S. Takahara, H. Sakuragi and K. Tokumaru, Chem. Lett., 1988, 17, 357.

14 J. Chateauneuf, J. Lusztyk and K. U. Ingold, J. Am. Chem. Soc., 1988, 110, 2886.

15 T. Najiwara, J. Hashimoto, S. Katsunori and H. Sakuragi, Bull. Chem. Soc. Jpn., 2003, 76, 575.

16 A. Kitamaru, H. Sakuragi, M. Yoshida and K. Tokumaru, Bull. Chem. Soc. Jpn., 1980, 53, 1393.

17 B. Abel, J. Assmann, P. Botschwina, M. Buback, M. Kling, R. Oswald, S. Schmatz, J. Schroeder and T. Witte, J. Phys. Chem. A, 2003, 107, 5157.

18 B. Abel, M. Buback, M. Kling, S. Schmatz and J. Schroeder, J. Am. Chem. Soc., 2003, 125, 13277.

19 B. Abel, J. Aßmann, M. Buback, M. Kling, S. Schmatz and J. Schroeder, Angew. Chem. Int. Ed., 2003, 42, 299.

20 B. Abel, J. Assmann, M. Buback, C. Grimm, M. Kling, S. Schmatz, J. Schroeder and T. Witte, J. Phys. Chem. A, 2003, 107, 9499.

21 J. Aßmann, M. Kling and B. Abel, Angew. Chem. Int. Ed., 2003, 42, 2226.

22 J. Aschenbrücker, M. Buback, N. P. Ernsting, J. Schroeder and U. Steegmüller, Ber. Bunsen-Ges. Phys. Chem., 1998, 102, 965.

23 J. Aschenbrücker, M. Buback, N. P. Ernsting, J. Schroeder and U. Steegmüller, J. Phys. Chem. B, 1998, 102, 5552.

24 (a) D. E. Falvey and G. B. Schuster, J. Am. Chem. Soc., 1986, 108 , 7419; (b) E. A. Morlino, M. D. Bohorquez, D. C. Neckers and A. A. J. Rodgers, J. Am. Chem. Soc., 1991, 113, 3599. 
25 T. M. Bockman, S. M. Hubig and J. K. Kochi, J. Org. Chem., 1997, 62, 2210.

26 H. J. Bakker, P. C. M. Planken and A. Langendijk, Nature, 1990, 347, 745.

27 D. Schwarzer, J. Troe and M. Zerezke, J. Chem. Phys., 1997, 107, 8380.

28 J. Aschenbrücker, M. Buback, N. P. Ernsting, J. Jasny, J. Schroeder and U. Steegmüller, Appl. Phys. B, 1997, 65, 441 .

29 J. Assmann, R. von Benten, A. Charvat and B. Abel, J. Phys. Chem. A, 2003, 107, 1904.

30 (a) A. D. Becke, J. Chem. Phys., 1993, 98, 5648; (b) C. Lee, W. Yang and R. G. Parr, Phys. Rev. B, 1988, 37, 785.

31 M. J. Frisch, G. W. Trucks, H. B. Schlegel, G. E. Scuseria, M. A Robb, J. R. Cheeseman, V. G. Zakrzewski, J. A. Montgomery, R. E. Stratmann, J. C. Burant, S. Dapprich, J. M. Millam, A. D. Daniels, K. N. Kudin, M. C. Strain, O. Farkas, J. Tomasi, V. Barone, M. Cossi, R. Cammi, B. Mennucci, C. Pomelli, C. Adamo, S. Clifford, J. Ochterski, G. A. Petersson, P. Y. Ayala, Q. Cui, K. Morokuma, D. K. Malick, A. D. Rabuck, K. Raghavachari, J. B. Foresman, J. Cioslowski, J. V. Ortiz, A. G. Baboul, B. B. Stefanov, G. Liu, A. Liashenko, P. Piskorz, I. Komaromi, R Gomperts, R. L. Martin, D. J. Fox, T. Keith, M. A. Al-Laham, C. Y. Peng, A. Nanayakkara, M. Challacombe, P. M. W. Gill, B. Johnson, W. Chen, M. W. Wong, J. L. Andres, C. Gonzalez, M. Head-Gordon, E. S. Replogle and J. A. Pople, GAUSSIAN 98 (Revision A.9): Gaussian Inc., Pittsburgh, PA, 1998.

32 (a) C. Gonzales and H. B. Schlegel, J. Chem. Phys., 1989, 90, 2154; (b) C. Gonzales and H. B. Schlegel, J. Phys. Chem., 1990, 94, 5523

33 (a) J. Pacansky, B. Liu and D. DeFrees, J. Org. Chem., 1986, 51, 3720; (b) J. Cioslowsky, G. Liu, M. Martinov, P. Piskorz and D. Moncrief, J. Am. Chem. Soc., 1996, 118, 5261.

34 (a) J. M. Wittbrodt and H. B. Schlegel, J. Chem. Phys., 1996, 105, 6574; (b) G. J. Laming, N. C. Handy and R. D. Amos, Mol. Phys., 1993, 84, 1121; (c) J. Baker, A. Scheiner and J. Andzelm, Chem. Phys. Lett., 1993, 216, 380.
35 F. H. Dorer and S. N. Johnson, J. Phys. Chem., 1971, 75, 3651.

36 K. W. Lee, D.-C. Kim and K.-H. Jung, J. Chem. Phys., 1999, 111, 1427.

37 S. K. Shin, S. O. Park, Y. S. Choi, H. L. Kim and C. R. Park, J. Phys. Chem. A, 2001, 105, 10018.

38 J. C. Scaiano and G. G. Wubbels, J. Am. Chem. Soc., 1981, 103, 640.

39 H. Yin, D. L. Hachey and N. A. Porter, Rapid Commun. Mass Spectrom., 2000, 14, 1248 .

40 (a) D. Schwarzer, J. Troe, M. Votsmeier and M. Zerezke, J. Chem. Phys. A, 1996, 105, 3121; (b) D. Schwarzer, J. Troe and M. Zerezke, J. Phys. Chem. A., 1998, 102, 4207; (c) D. Schwarzer, C. Hanisch, P. Kutne and J. Troe, J. Phys. Chem. A, 2002, 106, 8019.

41 J. I. Steinfeld, J. S. Francisco and W. L. Hase, Chemical Kinetics and Dynamics, Prentice Hall, Englewood Cliffs, NJ, 1989.

42 A. Kandratsenka and D. Schwarzer, private communication.

43 Note that in ref. 17 our analysis was based on the barrier height from quantum-chemical calculations on the UB3LYP/ $6-311+\mathrm{G}(2 \mathrm{df}, 2 \mathrm{pd}) / / 6-311+\mathrm{G}(\mathrm{d}, \mathrm{p})$ level.

44 J. Pacansky and D. W. Brown, J. Phys. Chem., 1983, 87, 1553.

45 S. Oishi, H. Tsubaki and H. Matsuzawa, Chem. Phys. Lett., 1999, 365, 805.

46 M. Kling and S. Schmatz, Phys. Chem. Chem. Phys., 2003, 5 3891.

47 (a) R. P. Bell, Trans. Faraday Soc., 1937, 33, 496; (b) M. G. Evans and M. Polanyi, Trans. Faraday Soc., 1936, 32, 1333.

48 Values from UB3LYP/6-311+G(d,p) calculations. $E_{0}$ includes corrections due to zero-point vibrational effects (harmonic level).

49 J. Wang, M. Tsuchiya, T. Tateno, H. Sakuragi and K. Tokumaru, Tetrahedr. Lett., 1994, 35, 6321.

50 J. Wang, M. Tsuchiya, T. Tateno, H. Sakuragi and K. Tokumaru, Chem. Lett., 1992, 21, 563.

51 A. Kandratsenka, J. Schroeder, D. Schwarzer and V. Vikhrenko, Phys. Chem. Chem. Phys., submitted. 